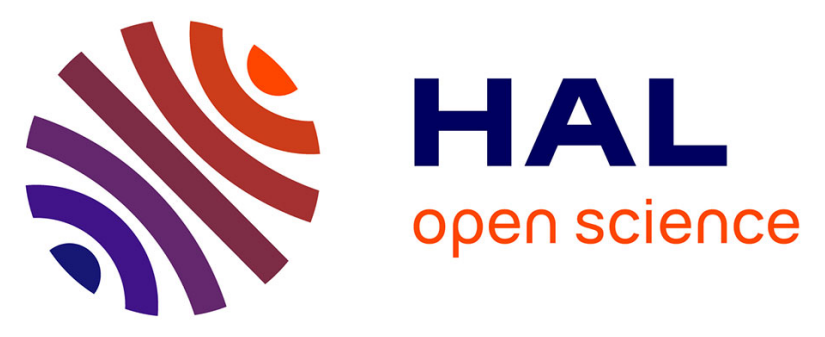

\title{
A numerical strategy to identify the FSW process optimal parameters of a butt-welded joint of quasi-pure copper plates
}

Monica Daniela Iordache, Claudiu Badulescu, Malick Diakhate, Marius Adrian Constantin, Eduard Laurentiu Nitu, Younes Demmouche, Matthieu

Dhondt, Denis Negrea

\section{To cite this version:}

Monica Daniela Iordache, Claudiu Badulescu, Malick Diakhate, Marius Adrian Constantin, Eduard Laurentiu Nitu, et al.. A numerical strategy to identify the FSW process optimal parameters of a butt-welded joint of quasi-pure copper plates: modeling and experimental validation. International Journal of Advanced Manufacturing Technology, 2021, 10.1007/s00170-021-07296-9 . hal-03252152

HAL Id: hal-03252152

https://hal-ensta-bretagne.archives-ouvertes.fr/hal-03252152

Submitted on 7 Jun 2021

HAL is a multi-disciplinary open access archive for the deposit and dissemination of scientific research documents, whether they are published or not. The documents may come from teaching and research institutions in France or abroad, or from public or private research centers.
L'archive ouverte pluridisciplinaire HAL, est destinée au dépôt et à la diffusion de documents scientifiques de niveau recherche, publiés ou non, émanant des établissements d'enseignement et de recherche français ou étrangers, des laboratoires publics ou privés. 


\title{
A numerical strategy to identify the FSW process optimal parameters of a butt-welded joint of quasi-pure copper plates: modelling and experimental validation
}

\author{
Monica Daniela IORDACHE ${ }^{\mathrm{a}}$, Claudiu BADULESCU ${ }^{\mathrm{b} *}$, Malick \\ DIAKHATE ${ }^{c}$, Marius Adrian CONSTANTIN ${ }^{\mathrm{a}}$, Eduard Laurentiu NITU ${ }^{\mathrm{a}}$, \\ Younes DEMMOUCHE ${ }^{\mathrm{b}}$, Matthieu DHONDT ${ }^{\mathrm{b}}$, and Denis NEGREA ${ }^{\mathrm{d}}$ \\ ${ }^{a}$ Manufacturing and Industrial Management Department, University of Pitesti, Pitesti, \\ Romania.
}

${ }^{b}$ ENSTA Bretagne, IRDL-UMR CNRS 6027, F-29200 Brest, France.

'Univ. Bretagne Occidentale, IRDL-UMR CNRS 6027, F-29600 Morlaix, France.

${ }^{d}$ Regional Center of Research \& Development for materials, processes and innovative products dedicated to the automotive industry (CRC\&D-Auto), University of Pitesti,

Pitesti, Romania.

*corresponding author

Claudiu Badulescu, claudiu.badulescu@ensta-bretagne.fr

\begin{abstract}
Determining the optimal parameters of the Friction Stir Welding (FSW) process, which are suitable for a given joint configuration, remains a great challenge and is often achieved through extremely time-consuming and costly experimental investigations. The present paper aims to propose a strategy for the identification of the optimal parameters for a butt-welded joint of 3-mm thick quasi-pure copper plates. This strategy is based on FEM (finite elements method) simulations and the optimal temperature that is supposedly known. A robust and efficient finite element model that is based on the Coupled Eulerian-Lagrangian (CEL) approach has been adopted and a temperature-dependent friction coefficient has been used. Besides, the mass scaling technique has been used to significantly reduce the simulation time. The thermo-mechanical behavior of the buttwelded joint was modeled using a Johnson-Cook plasticity model that was identified through lab tests at different temperatures. The results of the parametric study help to define the numerical surface response, and based on this latter one can found the optimal parameters, advancing $\left(v_{a}\right)$ and rotational $\left(v_{r}\right)$ speeds, of the FSW process. This numerical surface response has been validated with good agreement between the numerical prediction of the model and the experimental results. Furthermore, experimental investigations involving x-ray radiography, digital image correlation method, and fracture surface analysis have helped a better understanding of the effects of FSW parameters on the welded joint quality.
\end{abstract}


Keywords: Friction stir welding; Optimal process parameters; Cu-DHP copper; Finite element method; Mass scaling; Digital images correlation

\section{Introduction}

Copper and its alloys are widely used in many engineering applications since they have particular properties such as electrical and thermal conductivity, ductility, mechanical strength, corrosion resistance, etc. However, these materials are difficult to weld using conventional welding processes (fusion melting) because of the high thermal conductivity and the higher oxidation rate at temperature values close to fusion one [1]. Thus, an alternative and promising solution is friction stir welding (FSW). This joining process, environmentally friendly since it releases no toxic gas or radiations, is solid-state welding based on the generation of heat due to both the friction of the pin (rotating element) at the interface of the two plates to be joined and the plastic deformation of the material being welded. FSW is a metal-working process commonly characterized by a flow progressing through preheating, initial deformation, extrusion, forging, and cool-down processing zones. The rotating FSW pin plunges into the junction of two rigidly clamped plates until the shoulder touches the surface of the materials being welded before traversing along the weld line under the applied normal force $[2,3]$.

Many research studies have focused on the use of FSW to joint aluminum-based alloys, such as [4, 5, 6, 29], while limited literature on dissimilar FSW of copper is available. The limited research on FSW, and consequently its industrial application, is due to both the high melting point and the good thermal conductivity of the cooper as they lead to increasing the heat input during the welding process to obtain a joint without defects. This also results in higher requirements of materials and design of the welding tools. The effects of pin rotational speed on the microstructure, the mechanical properties, and the fracture localization of copper butt-joints have been investigated [7]. The effects of both the shoulder cavity and the welding parameters on the applied torque, the formation of weld defects, and the mechanical properties of deoxidized copper (thin films) butt-joints have been studied [8]. From the industrial point of view, the major challenge today is to able to predict the optimal welding parameters (advancing and rotational speeds of the pin), and many researchers have experimentally investigated this challenge [9, 10]. Most recently, some studies [11] have shown an optimal welding temperature at which the joint is free from defects, the homogeneity of the grain size 
within the joint is close to that of the base material, and the mechanical properties of the joint are optimum. This optimal temperature, which is associated with a welding configuration (material and geometry of the pin, the relative positioning of the parts to be welded) is often experimentally evaluated, thus leading to costly and long tests campaign. Furthermore, this optimal welding temperature seems to be an intrinsic parameter of the material, and the torque, the geometry of the pin, and the kinematics of the process help to achieve this temperature. Another recent study [12] used, for the first time, a fuzzy logic model to investigate and optimize the effect of FSW parameters on the tensile properties of the copper joints, such as ultimate tensile strength (UTS) and elongation. The microstructure of the optimum joint was characterized using different microscopy techniques to elucidate the origin of its behavior.

Several researchers have investigated the relationship between the microstructure of the welded assembly and the resulting mechanical properties. Findings from these studies show that the microstructural evolution of pure copper joint during the FSW process is mainly influenced by welding temperature. At temperature values lower than around 0.5 times $\mathrm{Tf}$ ( $\mathrm{Tf}$ being the material fusion temperature) the microstructure is mainly governed by continuous recrystallization. The grain structure development at welding temperature values greater than around 0.5 times $\mathrm{Tf}$ is mainly dominated by discontinuous recrystallization, thus resulting in a relatively coarse grain structure in the stir zone [35]. Dynamic and static changes of grain size and texture of copper during the FSW process have been studied by Xu et al.[36]. They have shown that during the plastic deformation stage, the initial coarse grains in the base metal were subdivided with the increase in strain and temperature, and the stir zone exhibits ultrafine grains with a large number of low angle boundaries and a symmetrical simple shear texture. The effect of stacking fault energy on the restoration mechanisms and the mechanical properties of joints has been studied by Heidarzadeh et al. [37]. Authors have shown that in pure copper the continuous dynamic recrystallization was the only restoration mechanism that leads to new grains formation. Moreover, the effect of restoration mechanisms on both the yield strength and the strain hardening of joints has been studied. For a deeper understanding, one can read the review paper recently published [38] which highlights the latest progress made in the microstructure analysis during the FSW process.

Based on the literature review [9, 10], one can identify the optimal parameters of the process through numerical simulations, thus leading to a drastic reduction of the 
experimental campaign. This finding highlights the importance of developing modeling strategies as well as efficient and robust numerical simulations. Today, the modeling of heat generation and material flow during the FSW process are addressed using different modeling techniques such as computational solid mechanics (CSM) and computational fluid dynamics (CFD) methods. The current literature proposes some approaches useful to tackle the mesh distortion. With this in mind, Al-Badour et al. [13] proposed the coupled Eulerian-Lagrangian (CEL) model. In this method, the plates being welded, governing the equations, are discretized using the Eulerian formulation whereas the welding tool is modeled as a Lagrangian body. These methods are based on explicit integration schemes which imply an extremely reduced step time, a high number of increments, and a high computational time. This is why most of the FSW numerical simulations are restricted to short computational times (penetration phase of the pin).

However, there are very few studies that propose robust numerical strategies and help to estimate the optimal process parameters without having to conduct extremely timeconsuming and costly experimental parametric studies.

The current work aims to develop an efficient strategy to determine the welding process parameters based on numerical simulations with the finite element method and the optimal temperature that is supposedly known for all materials that will be welded. The numerical model developed in this work should be able to simulate within a reasonable computational time (one to two days) an FSW process characterized by a welding time of about a few tens of seconds and a traversing length of the pin of about $100 \mathrm{~mm}$. The mass scaling technique is used to minimize the computational time. Also, the numerical model has enabled us to take into account the thermo-mechanical boundary conditions (heat exchange with the ambient air), the heat dissipation from plastic deformation, and that from the friction between the pin and the materials being welded. The friction coefficient was supposed as a function of the temperature.

This strategy has been used to simulate the butt welded joint of 3-mm thick quasi-pure copper and has been validated by comparison with experimental results (identification of defects using x-ray technique, local mechanical behavior of the joint analyzed using digital images correlation, and fracture surface analysis through fractography technique).

\section{Finite element model description}

\subsection{Finite element approach}


Numerical simulations have been conducted to assess the effect of different FSW process parameters on the quality of the FSW joints. Modeling the FSW process is a challenging task since it needs to address a multi-physical problem that is characterized by large plastic deformation and high temperature. The more difficult to suitably model is the material flow in the vicinity of the pin. Nowadays, several numerical simulation strategies are proposed to model the FSW process. In the non-flow-based models, excessive deformations appear and thus leads to early termination of the computation. The ALE formulation is often used to ensure a better mesh quality during the simulation [14]. However, because of extremely large deformations, this strategy cannot eliminate the mesh distortion and consequently leads to prohibitive computation time [15]. Recently, coupled Eulerian-Lagrangian (CEL) models have been developed to simulate severe plastic deformations [16]. CEL models, which were originally used to describe the thermo-mechanical response (forces and temperature distribution), now allows predicting defects (tunnel defects, cavities, and excess flash formation) that may occur [16].

In this work, a 3D thermomechanical finite element model based on the CEL formulation has been developed using ABAQUS software. The direct integration scheme was adopted, and the resolution was explicit. This integration scheme is well suited for problems that include numerous nonlinearities, dynamic phenomena, and thermal effects. The finite element model is described below.

\subsection{Geometry of the model and applied boundary conditions}

The two workpieces to be welded are $100 \mathrm{~mm}$ in length, $40 \mathrm{~mm}$ in width, and $3 \mathrm{~mm}$ in thickness. As shown in Fig.1-a, these workpieces are positioned into the Eulerian domain. This latter has a thickness of $3,5 \mathrm{~mm}$. The geometry of the tool has a conical shape with diameters of $4 \mathrm{~mm}$ at its base and $3 \mathrm{~mm}$ at its upper part and a length of $2.8 \mathrm{~mm}$ (Fig.1a). The tool is considered to be rigid and the workpieces deformable. All the lateral and bottom faces of the Eulerian domain are embedded. The tool is characterized by three movements. The first one is the rotation at a constant speed $\left(v_{r}\right)$ coupled with a penetration speed $\left(v_{p}\right)$ of about $2.8 \mathrm{~mm} / \mathrm{s}$ for all the simulations. Once the penetration step is completed, the tool will begin the actual welding phase over a distance of $90 \mathrm{~mm}$ in the $x$-direction (Fig. 1-a). During this latter, the tool keeps its rotational speed constant while at the same time it is subjected to an advancing speed. Several sets of parameters, which are characterized by different pairs of welding speed $\left(v_{r}, v_{a}\right)$ values are simulated. 
To save computational time, the tool retraction phase was not modeled. A constant ambient temperature field $\left(22^{\circ} \mathrm{C}\right)$ is applied to the whole Eulerian domain and at the beginning of the simulation. The heat exchange during the welding process has been taken into account by using a convection model that is characterized by a convection coefficient $\left(h_{f}\right)$ of $30 \mathrm{~W} / \mathrm{m}^{2} .{ }^{\circ} \mathrm{C}$ [17]. The heat exchange through the tool is not taken into account firstly to limit the size of the numerical model and secondly because of the low heat exchange that should be simulated since the thermal conduction coefficient of the copper remains relatively greater than the one of the tool. This step allows defining the boundary conditions at the surface to be welded.

\subsection{Mesh}

The Eulerian domain mesh comprises 6785 thermally coupled 8-node Eulerian elements (EC3D8RT) and 8364 nodes as shown in Fig.1-b. The mesh was progressively performed by increasing the element width from the joint line to the edge. The tool is a Lagrangian rigid body and was meshed using 785 quadratic tetrahedral elements. The mesh has been adapted based on the following two main reasons. The first one is to ensure that each part of the tool which comes into contact with the plates being welded has the same contact surface by ensuring a relatively homogeneous of both friction and local distribution of the contact pressure, with effects on the temperature field distribution. The second main reason is to ease the modeling of complex geometries such as the tool's one. The number of elements has been chosen in the view of obtaining a good compromise between the computation time and the convergence of the field temperature.

\subsection{Thermomechanical behavior of the material}

In this work, the material being welded is phosphorus deoxidized copper (DHP-Copper) with $99.9 \%$ pure copper. This material is commonly used in industry due to its good corrosion resistance, high thermal conductivity, and electrical conductivity [18]. The linear thermo-elastic behavior of the used material is described using the following constitutive equation [33] :

$$
\sigma=2 \mu \varepsilon_{e}+\lambda\left[\operatorname{tr}\left(\varepsilon_{e}\right)-\alpha\left(T-T_{0}\right)\right] \boldsymbol{I}
$$


Where $\boldsymbol{\sigma}$ is the stress tensor; $\boldsymbol{\varepsilon}_{\boldsymbol{e}}$ is the linear-elastic strain tensor; $\boldsymbol{\lambda}$ and $\boldsymbol{\mu}$ are the Lamé coefficients; $T$ is the real temperature, $\boldsymbol{T}_{0}$ is the reference temperature, $\boldsymbol{\alpha}$ is the thermal expansion coefficient, and I is the identity matrix.

The thermal field equation is expressed as follows [32]:

$$
-k \nabla^{2} T=\alpha \lambda T_{0} \operatorname{tr}\left(\dot{\boldsymbol{\varepsilon}}_{\boldsymbol{e}}\right)+\rho c_{e} \dot{T}
$$

Where $k$ is the thermal conductivity, $\rho$ is the density, and $c_{e}$ is the specific heat.

The first term on the right-hand side of the previous equation (Eq.2) describes the strain rate effect on the temperature field. The mechanical behavior is formulated using Navier's equations for thermoelectricity and is given hereafter [32]:

$$
\mu \nabla^{2} u+(\lambda+\mu) \nabla \operatorname{tr}\left(\boldsymbol{\varepsilon}_{e}\right)-\alpha \lambda \nabla T=\rho \frac{\partial^{2} u}{\partial t^{2}}
$$

Where $\mathbf{u}$ is the displacement vector and $\mathbf{t}$ is the time.

The physical properties of the DHP copper at room temperature are given in Table 1 . In this study, the Johnson-Cook's model is used to describe the material flow. The model uncouples the plastic, viscous, and thermal behaviors and describes each of them through three independents terms [20].

$$
\bar{\sigma}=\left[A+B \cdot\left(\overline{\varepsilon_{p}}\right)^{n}\right]\left[1+C \cdot \ln \left(\frac{\dot{\bar{\varepsilon}}_{p l}}{\dot{\varepsilon}_{0}}\right)\right]\left[1-\left(\frac{T-T_{r e f}}{T_{\text {melt }}-T_{\text {ref }}}\right)^{m}\right]
$$

Where $\bar{\sigma}$ is the flow stress; $\overline{\varepsilon_{p}}$ the effective plastic strain; $\dot{\bar{\varepsilon}}_{p l}$ the effective plastic strain rate; $\dot{\varepsilon}_{0}$ the normalizing strain rate; $A, B, C, n, T_{m e l t}$, and $m$ are material constants; $T_{r e f}$ the room temperature $\left(22^{\circ} \mathrm{C}\right.$ in this study).

In the previous equation (Eq.4), the parameter $n$ takes into consideration the hardening of the material, whereas $m$ depends on its fusion. $C$ is influenced by the strain rate. 
The material's constants were determined based on the experimental results from tensile tests that were carried out at different speeds $\left(3 \mathrm{~mm} \cdot \mathrm{min}^{-1}\right.$ and $\left.30 \mathrm{~mm} \cdot \mathrm{min}^{-1}\right)$, which are equivalent to strain rates of $1.67 \times 10^{-2} \mathrm{~s}^{-1}$ and $1.67 \times 10^{-3} \mathrm{~s}^{-1}$ and temperatures $\left(22^{\circ} \mathrm{C}, 300^{\circ} \mathrm{C}\right.$, and $\left.500{ }^{\circ} \mathrm{C}\right)$. During the $\mathrm{FSW}$ process, the applied strain rate can sometimes, depending on the welding configuration to perform, reach $1600 \mathrm{~s}^{-1}[30,31]$. Nevertheless, such high-performance equipment is not available in our research entities. The inverse identification method was used. A hydraulic testing machine (INSTRON 1342) equipped with a load cell (+/-100 kN capacity) was used to apply the loading rate and a climatic test chamber (CERHEC 1400), which can generate a controlled temperature for up to $1500^{\circ} \mathrm{C}$, helps regulate the testing temperature. For the sake of clarity, only results from tests at $22^{\circ} \mathrm{C}$ and $500^{\circ} \mathrm{C}$ are presented in Fig. 2 .

The identified values of the constants of Johnson-Cook's model for DHP copper are obtained by fitting the equation (Eq.4) with the experimental results and are shown in Table 2.

\subsection{Friction model}

A critical aspect of the FSW process simulation is the contact condition modeling between the tool and the plates being welded since the Eulerian domain interacts with the Lagrangian one. Many studies have focused on the development of contact models suitable for the FSW process. Most of them have opted for a friction coefficient that is kept constant during the simulation $[21,22]$. However, the friction coefficient depends on speed, temperature, and deformation rate. Recently, Kareem et al. [23] have used the Coulomb friction model with a non-linear coefficient that is dependent on both the local temperature of the melted material and the deformation rate. This evolution of the coefficient has been previously proposed by Meyghani et al. [24] through a highly original work that integrates the shear stress of the contact interface (dependent on the temperature), the partial sliding/ sticking condition, and the geometry of the tool.

Very promising results from experimental tests [24], which were carried out using various FSW parameter sets, have validated this evolution of the friction coefficient as a function of temperature. Thus, this methodology was used in this work to describe the relationship between the friction coefficient evolution and the temperature (Fig.3). At ambient temperature, $\mu_{0}=0.22$ (evaluated by using the inverse identification method).

\subsection{Mass scaling strategy}


In the FEM model, an explicit integration scheme was used for the resolution. One of the major criticisms of this integration scheme is the extremely long computational time that is associated with it, so it is mainly used for dynamic simulations (simulation time relatively short). If the time increment is less than a critical value $\Delta t_{c r i t}$, the integration scheme is considered as conditionally stable. The critical time increment $\Delta t_{\text {crit }}$ is computed from the mass and stiffness characteristics of the model and is expressed as follows [34]:

$$
\Delta t_{c r i t}=\min \left(\frac{L_{c i}}{C_{d}}\right)
$$

Where $C_{d}=\sqrt{\frac{E}{\rho}}$ is the wave propagation velocity within the material and $L_{c i}$ is the characteristic length of each element ' $i$ ' of the mesh.

Mass scaling is a way of reducing the computational time, and it increases artificially the masses of the elements and can be applied even though there is rate dependency. The mass (Eq.3) is scaled by replacing the density term $\rho$ with the fictitious density $\rho^{*}=\kappa_{m}$. $\rho$, with $\kappa_{m}>0$ [32]. The mass scaling factor $\kappa_{m}$ has to be chosen in such a way that the inertial forces, the right-hand side of the equation (Eq.3), remain small. The substitution of the density $\rho$ for a fictitious density $\rho^{*}$ leads to a change in the thermal time constant (Eq.2). This effect can be compensated by introducing the fictitious specific heat $c_{e}^{*}=$ $c_{e} \kappa_{m}^{-1}$. Thus, we obtained the two following scaled thermo-elastic equations (Eq.6 and Eq.7). Mass inertia effects can be seen explicitly on the right-hand side of the equation (Eq.6) [32].

$$
\begin{aligned}
& -k \nabla^{2} T=\alpha \lambda T_{0} \operatorname{tr}\left(\dot{\boldsymbol{\varepsilon}}_{\boldsymbol{e}}\right)+\rho^{*} c_{e}^{*} \dot{T} \\
& \mu \nabla^{2} \boldsymbol{u}+(\lambda+\mu) \nabla \operatorname{tr}\left(\boldsymbol{\varepsilon}_{\boldsymbol{e}}\right)-\alpha \lambda \nabla T=\rho^{*} \frac{\partial^{2} \boldsymbol{u}}{\partial t^{2}}
\end{aligned}
$$

To achieve a reasonable accuracy of simulation results, the ratio of kinetic energy to internal one must be less than $2 \%$ of the simulated model. According to [17], a value of $\kappa \mathrm{m}=1000$ was chosen. Thus, the temperature error is less than $10 \%$ and the computational time is reduced by 25 times. As a consequence, the use of the mass scaling method 
combined with a reasonable computational time leads to a significant reduction in the increments number as well as the inherent numerical errors.

\section{Validation of the finite element model}

To allow validation of the FEM, two DHP copper plates with dimensions of $100 \mathrm{~mm}$ (length) x $100 \mathrm{~mm}$ (width) x $3 \mathrm{~mm}$ (thickness) have been welded with two sets of welding parameters. The assembly process is performed by using a welding machine FSW-4-10 that is characterized by a rotating speed in the range of 300 to $1450 \mathrm{rpm}$ and an advancing speed between 10 and $480 \mathrm{~mm} / \mathrm{min}$. Throughout the welding process, this machine also allows both controlling the displacement and recording the force in the $\vec{z}$ direction (Fig.1b). The temperature has been measured using an infrared camera (FLIR A40M) with an accuracy of $+/-2^{\circ} \mathrm{C}$, and at the interface between the tool and the plates being welded (precisely at $1 \mathrm{~mm}$ behind the tool and pointing to the weld bead). The infrared camera moves with the tool.

The first welded assembly, which is labeled W-90-800, was obtained with an advancing speed of $90 \mathrm{~mm} / \mathrm{min}$ and a rotating speed of $800 \mathrm{rpm}$. The second welded assembly, which is labeled W-90-1000, was obtained with an advancing speed of $90 \mathrm{~mm} / \mathrm{min}$ and a rotating speed of $1000 \mathrm{rpm}$. The rotational speed value of the tool was modified while the advancing one was kept constant. This choice was motivated by the fact that the welding temperature increase is mainly influenced by the rotational speed than the advancing one and this temperature value could be less affected by measurement errors.

The evolution of maximal welding temperature is plotted against the position of the tool during the welding of W-90-1000 (Fig.4). This first result helps to evaluate the initial value of the friction coefficient $\mu_{0}$ (Fig.3) by minimizing the difference between values that are predicted by the model and those obtained from the experimental measurements. Once the value of $\mu_{0}$ identified, the validity of the numerical model can be evaluated by comparing the temperature distribution measured within the second welded assembly during the tool advance with the one predicted by the finite element model (Fig.5). Moreover, the numerical axial force is compared with the experimental one (Fig.5-b). These findings indicate that the experimental results are in good agreement with those obtained from the numerical simulation, the force axial error is less than $6 \%$. 


\section{Parametric study}

It has been proven [1] that it is crucial to reach the optimal welding temperature for obtaining a welded joint of high quality characterized by a mechanical strength close to that of the base material. This temperature can be experimentally evaluated and is about 0.4 to 0.5 times $\mathrm{T}_{\text {melt }}$ for quasi-pure copper materials [1]. The optimal welding temperature of DHP copper materials $[1,25]$ is about $550^{\circ} \mathrm{C}$. At this temperature, the base material is in a pasty state, so this allows a homogeneous melting while avoiding defect formation. If this temperature is exceeded and approaching that of melting, the material becomes too fluid, which will result in both voids formation within the joint and inhomogeneous melting. This latter also leads to excessive burr of the weld bead and, under tensile loading, fracture at the welded joint.

This parametric study aims at carrying out numerous simulations which subsequently will help to identify the optimal welding parameters. Twelve simulations are carried out using the welding parameters specified in Table 3. Each simulation is individually labeled, indicating the speeds of both advancing and rotating.

For instance, Fig.6-a shows the computation field temperature obtained during the simulation of the welding configuration S-90-1000 and precisely when the tool position is at $85 \mathrm{~mm}$ from point A. As shown in Fig.5-a, both experimentally and numerically, the welding temperature takes time to reach its optimal value. In these welded areas where the temperature is not stabilized, defects likely have appeared. Consequently, for each numerical simulation, the temperature is recorded at a tool position greater than $85 \mathrm{~mm}$ from point A. These temperature values are shown in Fig.6-b by the red points. For a clear presentation of these temperature results, a polynomial surface interpolation was performed. This highlights the effects of the FSW process parameters on the stabilized welding temperature. This finding is in good agreement with experimental observations [28]. At a given advancing speed $v_{a}$, the stabilized temperature increases with the rotating speed $v_{r}$. However, when this latter is fixed, a decrease in the advancing speed leads to an increase in the stabilized process temperature.

\section{Simulation Results}

From the obtained results one can compute a thermal efficiency surface indicator $\left(\boldsymbol{T}_{\boldsymbol{E}}\right)$ that is defined in the following formula (Eq.8): 


$$
\boldsymbol{T}_{E}\left(v_{a}, v_{r}\right)=\left[1-\frac{a b s\left[\boldsymbol{T}_{S}\left(v_{a}, v_{r}\right)-\boldsymbol{T}_{\boldsymbol{O}}\right]}{\boldsymbol{T}_{\boldsymbol{O}}}\right] \times 100
$$

Where $\boldsymbol{T}_{S}\left(v_{a}, v_{r}\right)$ represents the stabilized temperature obtained from the simulation with the speeds $v_{a}$ and $v_{r}$, and $T_{O}$ represents the optimal welding temperature identified from the literature $[25,1]$. The maximal value of the indicator $T_{E}$ might give a valuable indication of the optimal area of the welding process.

The thermal efficiency surface $\left(T_{E}\right)$ mapping is shown in Fig.7.

This mapping clearly shows an area, the one colored in red, that is characterized by values of $T_{E}$ close to $100 \%$, in other words, by stabilized temperature values close to the temperature $T_{O}$. This result means that, inside that particular area, one can identify FSW process parameters that help to obtain welded joints with mechanical strengths close to that of the base material. Ideally, it is recommended to perform the welding at relatively high speeds $\left(v_{a}=120 \mathrm{~mm} / \mathrm{min}\right.$ and $\left.v_{r}=1150 \mathrm{rpm}\right)$ to avoid heat loss in the weld bead, but also to increase productivity. It should be noticed that these values could be limited due to both the kinematics and rigidity of the welding machine. Conversely, selecting low optimal values leads to the use of both moderate kinematics and less effective welding machines, on the condition that the heat losses did not become too high. In this parametric study, only the heat exchange with the ambient air is integrated into the model. However, evaluating the effects of more realistic thermal boundary conditions remains possible.

From Fig.7, the optimal dependency between the rotating speed and the advancing one might be expressed as follows (Eq.9).

$$
v_{r}=k_{T} \times v_{a}+k_{r}
$$

With $k_{T}=5.52 \mathrm{rot} / \mathrm{mm}$ and $k_{r}=483 \mathrm{rot} / \mathrm{min}$. These two constants depend on both the tool geometry and the material being welded. Their values are identified from the equation of the black-colored line plotted in Fig.7. 
The equation (Eq.8) allows evaluating the optimal value of the tool rotating speed based on an imposed advancing speed value. Some experimental tests are then needed to both validate this strategy and evaluate the difference between the stabilized temperature and the optimal one $\left(T_{O}\right)$, as well as the joint strength.

\section{Experimental validation}

\subsection{Experimental setup}

In addition to two welding configurations (labeled W-90-800 and W-90-1000) that were used for both identification and validation of the finite element model, five other FSW assemblies have been manufactured using the same material (Cu-DHP) and geometry (length, width, and thickness). The labels (process parameters) of the five other welding configurations are specified in Table 4. The non-destructive testing using penetrating radiation (X-ray radiography) was performed on ANDREX X-ray Equipment model CMA357 using high contrast, very fine grain KODAK INDUSTREX T200 Film. The focal distance was $50 \mathrm{~cm}$, current intensity $2 \mathrm{~mA}$, working voltage $120 \mathrm{~kW}$, and the exposure time $1 \mathrm{~min}$ and was performed on four specimens (labeled W-90-1200, W-1501200, W-90-800, and W-150-800). This investigation aims at qualitatively evaluating the presence or absence of defects having a dimension greater than $300 \mu \mathrm{m}$ within the joint. For each FSW specimen, the investigated volume size is graphically represented by the blue-colored parallelepiped shown in Fig.8-b. The x-rays pass through the specimen, and two of its faces (Fig.8-b) are projected for the defects analysis: the frontal one bounded by points $\mathrm{A}, \mathrm{B}, \mathrm{C}$, and $\mathrm{D}$, and the lateral one bounded by points $\mathrm{B}, \mathrm{F}, \mathrm{E}$, and $\mathrm{C}$.

For each welding configuration to be investigated through monotonic tensile tests, three specimens have been extracted from the welded stabilized area and at the following positions (from point A, Fig.5-a): $55 \mathrm{~mm}, 70 \mathrm{~mm}$, and $85 \mathrm{~mm}$ respectively. The geometry of the extracted specimens is shown in Fig.8-a. Additional details about the specimen geometry are $l_{0}=100 \mathrm{~mm}$ and $L=200 \mathrm{~mm}$.

During tensile tests, the Digital Images Correlation (DIC) method was used to monitor the local strain field $\varepsilon_{y y}$ simultaneously on both the frontal face (area bounded by points G, H, I, and J in Fig.8-b) and lateral face (area bounded by points H, K, L, and I in Fig.8b).

The experimental setup used to measure the displacement field on the above-mentioned faces is shown in Fig.9 
The testing machine used to investigate the mechanical behavior of the welded joint is the same as that for the thermo-mechanical characterization of the base material, namely INSTRON 1342. Monotonic tensile tests were performed at a loading rate of $3 \mathrm{~mm} / \mathrm{min}$. The displacement field measurement on the two perpendicular faces (frontal and lateral) of the sample, was performed by simultaneously using two CCD cameras that are fully synchronized with the INSTRON machine: an Aramis-GOM system equipped with a 2448 × 2050 pixels CCD sensor and a Retiga 6000 equipped with a 2758 x 2208 pixels CCD sensor. The resulting strain field is computed by deriving the displacement field.

Before installing the specimen in the testing machine, its two perpendicular faces were speckled and on an area of interest which is $45 \mathrm{~mm}$ long and centered on the welded joint (Fig.8-b). This length has been selected so that a wide area around the welded joint can be monitored and recorded up to failure. A polarized lighting device was also set up for recording images with high contrast at a frequency of $1 \mathrm{~Hz}$.

The mechanical loading is applied along the $\vec{y}$-direction (Fig.8). For image analysis, the spatial resolution is set to 19 pixels, and the standard deviation of the displacement field to $+/-0.5 \mu \mathrm{m}$.

To complete this experimental investigation, a digital microscope (KEYENCE VHX) was used to analyze the fracture surfaces of three specimens (labeled W-90-1000, W-1201000, and W-150-1000) at 100x magnification to highlight the failure scenario through different zones of FSW joints.

\subsection{Results from X-ray analysis}

The results from the X-ray analysis of the four specimens are shown in Fig.10.

As shown in Fig.10, false-color images of the above-mentioned faces (frontal and lateral) allow detection of the defects along both the axis (y-direction) and width (z-direction) of the joint.

From image analysis, it can be noticed that there is no detectable defect within the specimen labeled W-90-1000 (Fig.10-a). Consequently, this FSW specimen should exhibit higher mechanical properties (maximum values of stress and strain at failure). The defects detected within the specimen labeled W-150-1000 (Fig.10-b) seem to be a tunnel type defect, are characterized by a variation in its width along the welding direction and are located in the root of the weld (retreating side). The defects within the two other specimens labeled W-80-800 and W-150-800 (Fig.10-c and Fig.10-d, respectively) have 
a size bigger than that of those detected within the specimen labeled W-90-1000, extend over the whole width of the specimen, are located in the root of the weld (retreating side) and characterized by a $1 \mathrm{~mm}$ in depth. These specimens are likely to exhibit low mechanical strength.

\subsection{Results from monotonic tensile tests}

The macroscopic mechanical responses of the welding configurations that were tested under tensile load (Table 4) are shown in Fig.11. In this figure, the true stress $\left(\overline{\sigma_{v}}\right)$ is plotted as a function of the logarithmic strain $\left(\overline{\varepsilon_{v}}\right)$.

Results from tensile tests (Fig.11) highlight the effects of the welding parameters on the macroscopic mechanical behavior of the welded joint. For some process parameters, the values of both the logarithmic strain and true stress at the specimen failure are close to the ultimate strength of the base material. For a suitable analysis of the results, the mechanical efficiency $E_{M}$ of the joint is computed by using the following formula:

$$
E_{M}\left(v_{a}, v_{r}\right)=\frac{\bar{\sigma}_{v \max } F S W\left(v_{a}, v_{r}\right)}{\bar{\sigma}_{v \max } B M} \times 100
$$

Where $\bar{\sigma}_{v \text { max }} F S W$ represents the maximum value of the true stress resulting from the tensile test on an assembly welded at the speeds $\left(v_{a}, v_{r}\right)$ and $\bar{\sigma}_{v} \max B M$ represents the maximum value of the true stress of the base material. Based on the results shown in Fig.11 and Fig.2, $E_{M}$ values are plotted on Fig.12-a as a function of the two welding speeds $\left(v_{a}, v_{r}\right)$. This result (Fig.12-a) highlights an area, around the white-colored line, within which the selected welding speeds lead to a joint characterized by a mechanical efficiency value close to $90 \%$. It is also clear from Fig.12-a that one can notice a very good correlation between the mapping of the $E_{M}$ values and that of the thermal efficiency surface $\left(T_{E}\right)$ values. Moreover, Fig.12-b shows a good agreement between the welding speeds $\left(v_{a}, v_{r}\right)$ selected from the mapping of the $T_{E}$ values and the resulting strain value at specimen failure $\left(\bar{\varepsilon}_{v} \max F S W\right)$. These findings validate the strategy for identifying the optimal process parameters.

The maximum strain $\left(\bar{\varepsilon}_{v} \max F S W\right)$ value is around 0.3 when the welding is performed at the optimal process speeds, and that strain value is close to the one obtained when the base material fails. The key parameter for manufacturing a joint of high quality is mainly 
governed by the welding temperature obtained in the vicinity of the tool. Optimizing this welding temperature prevents the generation of both tunnel and kissing bond defects.

\subsection{Strain maps results}

Differences between the macroscopic behavior of FSW joints (Fig.11) could be better explained by analyzing the local behavior of the different zones of the joint. For this purpose, the strain fields $\left(\varepsilon_{y y}\right)$ obtained on both faces (frontal and lateral) of the specimens W-90-1000 and W-150-1000 are shown in Fig.13. Local strain maps (in the loading direction) resulting from seven different values of macroscopic stress (Fig.13-a) are compared. As stated previously, the analysis of X-ray results allows concluding that the defects detected within the specimen W-150-1000 are of tunnel type. This explains why the yield strength of that specimen is lower than that of the specimen labeled W-901000. From Fig.13-b, one can see on the strain maps of the lateral face (W-150-1000) that the defect starts appearing at a stress value of around $130 \mathrm{MPa}$ (from point C, Fig.13-a). This localization reflects the tunnel defect propagation from the root of the joint to the welded area.

This propagation scenario is highlighted on strain maps labeled $\mathrm{d}$ and e. The sudden decrease in the macroscopic stress value of the specimen W-150-1000 is because of the sudden propagation of the defect to the opposite face.

When analyzing the strain field on each frontal face of the two specimens, one can see that the defect starts being detected from the stress level labeled d. These localizations are undoubtedly associated with defect propagation. From these strain maps, one can also notice that defects are located on the retreating side and their appearance leads to high strain values in their vicinity. Under the same loading rate level, the highest strain value is about 0.2 for the specimen W-150-1000 and 0.02 for the specimen W-90-1000.

To better understand the mechanisms that govern the fracture of joints, fracture surface analysis was performed on three specimens (labeled W-90-1000, W-120-1000, and W150-1000) using a high-resolution digital microscope. The results are shown in Fig.14.

From Fig.14, one can notice a cross-section reduction of about $67.5 \%, 30.6 \%$, and $15.9 \%$ for the specimen W-90-1000, W-120-1000, and W-150-1000 respectively. The specimen W-90-1000 exhibits a ductile fracture. Periodic striations are observed on the fracture

surface of specimens W-120-1000 and W-150-1000. Similar striations have already been observed [26] on the fracture surface of an aluminum AA5083-H112 alloy FSW joint. 
Zettler et al. [27] have observed machining grooves that can be associated with the tool advancing along both the cross-section and welding direction of an aluminum AA6063T6 alloy FSW joint.

In the present study, the striations at the fracture surface of $\mathrm{W}-120-1000$ are localized in its lower side of the FSW joint and at a periodic interval. The localization of these striations in the lower half of the cross-section highlights the fact that the insufficient temperature at the root of the weld does not ensure melt quality, thus leading to the appearance of kissing bond defects. By comparing the specimens W-120-1000 and W150-1000 (having the same rotating speed but different advancing speed), one can observe striations over the entire cross-section of the specimen W-150-1000 and are distributed at low density compared to the specimen W-120-1000. This pattern was more pronounced at the root of the weld.

\subsection{Microstructure, microhardness, and fracture surfaces}

Microstructure and microhardness of joints have been analyzed and compared to those from specimens obtained under extreme welding conditions, i.e. based on thermal and mechanical efficiency surface indicators $T_{E}$ and $E_{M}$. Thus, the configuration W-90-1000 was obtained with the best indicators and the configuration W-150-1000 with the worst one (Fig.16). The microstructures of both the base material and the weld nugget were analyzed for the two above-mentioned welding configurations. For each of these, the specimen dedicated to the microstructure analysis was the one located in the vicinity of the specimen mechanically tested. The lateral face of the specimen was first polished to a depth of $3 \mathrm{~mm}$ using 600 to 1200 grit papers before it received a diamond polishing ( $3 \mu \mathrm{m}$-granularity) to achieve a smooth and even surface. Then, a chemical attack, which was formulated with $50 \%$ of distilled water and $50 \%$ of $\mathrm{HNO}_{3}$, was performed for 30 seconds and followed by rinsing with ethanol. One can see that the microstructure of the base material (Fig.16-a) is quite uniform and polyhedral, and is composed of grains having an average size of about $35 \mu \mathrm{m}$. The microstructure of the weld nugget of the specimen W-90-1000 (Fig.16-b) is less uniform and is composed of grains having a smaller average size $(21 \mu \mathrm{m})$ and strongly deformed with diffuse edges compared to those of the base material. In Fig.16-d, one can see that the weld nugget of the specimen W150-1000 is composed of grains having an even smaller average size (about $15 \mu \mathrm{m}$ ) than those of the weld nugget of W-90-1000. The welding temperature determines the dynamic 
recrystallization of the material in both configurations. However, the lower welding temperature of the configuration W-150-1000 led to the appearance of grains having an average size smaller than the one of grains from W-90-1000. This has also influenced the microhardness of both configurations (Fig.16-c). The microhardness of W-150-1000 is higher than the one of W-90-1000. However, the insufficient heat induced by the welding of W-150-1000 did not allow the material to be in its optimal plastic state, thus generating weld defects of type "kissing bond" (Fig.16-f). This type of defect has not been detected in the configuration W-90-1000 (Fig.16-e).

One last result is about the failure localization referring to the joint axis. Fig. 15 shows the observations from each welding configuration tested. It can be seen that among the seven tested specimens only the welding configuration W-90-1000 exhibits a fracture path localized outside the welded joint. This indicates that for this specimen, the process parameters (welding speeds) are optimal.

Moreover, one can notice that for each of the other FSW configurations, the resulting fracture path is localized within the weld bead and always at the retreating side (RS). These findings are in good agreement with the prediction of the optimum parameters.

\section{Conclusion}

This work has enabled us to study the friction stir welding process applied on a quasipure copper material. A robust and efficient numerical strategy is proposed and aims at predicting the optimal welding parameters for which a butt joint welding of 3-mm thick quasi-pure copper exhibits the maximum values of both mechanical strength and strain to fracture.

The simulation tool, which is based on the CEL (Coupled Eulerian-Lagrangian) model, takes into account some key aspects that make it robust and efficient: firstly, a friction coefficient that depends on the temperature has been used and its initial value was computed based on the ambient temperature and using the inverse identification method; secondly, the computational time has been reasonably optimized (two days for the welding configurations simulated in this work) thanks to the use of the mass scaling technique, which has a low impact of the accuracy of the results since the temperature field is lowly overestimated (less than 10\%); thirdly, the values of the constants of Johnson Cook's law were determined experimentally. 
The key parameter of this simulation strategy lies in evaluating the optimum value of the welding temperature, which is intrinsic to both the welding configuration and material. This optimum value of welding temperature can be often found in the literature. However, for welding configuration that has never been studied, this optimum welding temperature could be identified through extremely long and costly experimental investigation. Thus, the simulation model developed in this work allows identifying the best combinations of welding speeds $\left(v_{a}, v_{r}\right)$. An extensive testing campaign involving tensile test, X-ray technique, analysis of local strain fields, analysis of fracture surfaces highlights the robustness of the simulation strategy proposed in this work. The experimental results were in good agreement with the FE simulations and then have enabled us to determine the suitable set of FSW parameters for the studied material.

\section{Acknowledgments}

This work was supported by a grant of the Romanian Ministry of Research and Innovation, CCCDI-UEFISCDI, project number PN-III-P3-3.1-PM-RO-FR-20190048/01.07.2019 and Campus FRANCE, France

\section{Declarations}

\section{Ethical Approval}

Not applicable

\section{Consent to Participate}

Not applicable

\section{Consent to Publish}

Not applicable

\section{Authors Contributions}

Monica Daniela IORDACHE - conceived of the presented idea and supervised the project

Claudiu BADULESCU - developed the theory and performed the computations

Malick DIAKHATE - wrote the manuscript in consultation with Claudiu BADULESCU 
Marius Adrian CONSTANTIN - designed and performed the experiments

Eduard Laurentiu NITU - involved in planning and supervised the work, the analysis of the results, and the writing of the manuscript

Younes DEMMOUCHE - aided in interpreting the results and worked on the manuscript

Matthieu DHONDT - aided in interpreting the results and worked on the manuscript

Denis NEGREA - performed the x-ray radiography measurements

All authors discussed the results and commented on the manuscript

\section{Funding}

The research reported was founded partially by "Romanian Ministry of

Research and Innovation, CCCDI-UEFISCDI, project number PN-III-

P3-3.1-PM-RO-FR-2019-0048/01.07.2019" and "Campus FRANCE",

France

Conflicts of interest/Competing interests (include appropriate disclosures)

We know of no conflicts of interest or personal relationships that could have appeared to influence the work reported in this paper

\section{Availability of data and material}

Not applicable

\section{Code availability}

Not applicable

\section{References}

[1] Hwang, Y.M., Fan, P.L., Lin, C.H. Experimental study on Friction Stir Welding of copper metals. J Mater Process Technol 210(12), 1667-1672 (2010). https://doi.org/10.1016/j.jmatprotec.2010.05.019 
[2] Thomas, W.M., Nicholas E.D., Needham J.C., et al. inventors; The Welding Institute, TWI, International Patent Application No. PCT/GB92/02203 and GB Patent Application No. 9125978.8. 1991 Dec

[3] Galvão, I., Loureiro, A., Rodrigues, D.M. Critical review on friction stir welding of aluminium to copper. Sci Technol Weld Joining 21(7), 523-546 (2016). https://doi.org/10.1080/13621718.2015.1118813

[4] Cole, E.G., Fehrenbacher, A., Duffie, N.A. et al. Weld temperature effects during friction stir welding of dissimilar aluminum alloys 6061-t6 and 7075-t6. Int J Adv Manuf Technol 71, 643-652 (2014). https://doi.org/10.1007/s00170-013-5485-9

[5] Dourandish, S., Mousavizade, S.M., Ezatpour, H.R. et al. Microstructure, mechanical properties and failure behaviour of protrusion friction stir spot welded 2024 aluminium alloy sheets. Sci Technol Weld Joining23(4), 295-307 (2018). https://doi.org/10.1080/13621718.2017.1386759

[6] Jacquin, D., Guillemot, G. A review of microstructural changes occurring during FSW in aluminium alloys and their modelling. J Mater Process Technol 288, yyy-yyy (2021) https://doi.org/10.1016/j.jmatprotec.2020.116706

[7] Zhou, L., Zhang, R.X., Hu X.Y. et al. Effects of rotation speed of assisted shoulder on microstructure and mechanical properties of 6061-T6 aluminum alloy by dual-rotation friction stir welding. Int J Adv Manuf Technol 100, 199-208 (2019) https://doi.org/10.1007/s00170-018-2570-0

[8] Leal, R.M., Sakharova, N., Vilaça, P. et al. Effect of shoulder cavity and welding parameters on friction stir welding of thin copper sheets. Sci Technol Weld Joining 16(2), 146-152 (2011). https://doi.org/10.1179/1362171810Y.0000000005

[9] Ramachandran, K.K., Murugan, N., Shashi Kumar, S. Performance analysis of dissimilar friction stir welded aluminium alloy AA5052 and HSLA steel butt joints using response surface method. Int $\mathbf{J}$ Adv Manuf Technol 86, 2373-2392 (2016) https://doi.org/10.1007/s00170-016-8337-6

[10] Shashi Kumar, S., Murugan, N., Ramachandran, K.K. Identifying the optimal FSW process parameters for maximizing the tensile strength of friction stir welded AISI 316L $\begin{array}{lllll}\text { butt joints. } & \text { Measurement 137, 257-271 }\end{array}$ https://doi.org/10.1016/j.measurement.2019.01.023

[11] Zhang, W., Liu. H., Ding, H. et al. The optimal temperature for enhanced lowtemperature superplasticity in fine-grained $\mathrm{Ti}-15 \mathrm{~V}-3 \mathrm{Cr}-3 \mathrm{Sn}-3 \mathrm{Al}$ alloy fabricated by friction stir processing. J Alloys Compd. 832 yyy-yyy (2020) https://doi.org/10.1016/j.jallcom.2020.154917

[12] Heidarzadeh, A., Testik, Ö.M., Güleryüz, G. et al. Development of a fuzzy logic based model to elucidate the effect of FSW parameters on the ultimate tensile strength and elongation of pure copper joints, J Manuf Processes53, 250-259 (2020), https://doi.org/10.1016/j.jmapro.2020.02.020 
[13] Al-Badour, F., Merah, N., Shuaib, A. et al. Coupled Eulerian Lagrangian finite element modeling of friction stir welding processes. J Mater Process Technol. 213,14331439 (2013). https://doi.org/10.1016/j.jmatprotec.2013.02.014

[14] Bussetta, P., Dialami, N., Boman, R. et al. Comparison of a fluid and a solid approach for the numerical simulation of friction stir welding with a non-cylindrical pin. Steel Res Int 85(6), 968-979 (2014)

[15] Dialami, N., Chiumenti, M., Cervera, M. et al. Material flow visualization in friction stir welding via particle tracing. Int $J$ Mater Form 8, 167-181 (2015). https://doi.org/10.1007/s12289-013-1157-4

[16] Chauhan, P., Jain, R., Pal, S.K. et al. Modeling of defects in friction stir welding using coupled Eulerian and Lagrangian method. J Manuf Processes A 34,158-166 (2018). https://doi.org/10.1016/j.jmapro.2018.05.022

[17] Constantin, M.A., Iordache, M.D., Nitu, E.L. et al. An efficient strategy for 3D numerical simulation of friction stir welding process of pure copper plates. IOP Conf. Ser.: Mater. Sci. Eng. 916012021 , ModTech International Conference - Modern Technologies in Industrial Engineering VIII. 2020, June 23-27, Iasi, Romania. doi:10.1088/1757-899X/916/1/012021

[18] Galvão, I., Leal, R.M., Rodrigues, D.M. et al. Influence of tool shoulder geometry on properties of friction stir welds in thin copper sheets. J Mater Process Technol 213(2), 129-135 (2013). https://doi.org/10.1016/j.jmatprotec.2012.09.016

[19] Physical and Mechanical Properties of Pure Copper, http://wwwferp.ucsd.edu/LIB/PROPS /PANOS/cu.html (accessed on 25.02.2019).

[20] Johnson, G.R., Cook, W.H. A constitutive model and data for metals subjected to large strains, high strain rates and high temperatures. Proceedings 7th International Symposium on Ballistics, 1983 April 19-21. p. 541-547. The Hague, Netherlands

[21] Chiumenti, M., Cervera, M., Agelet de Saracibar, M. et al. Numerical modeling of friction stir welding processes. Comput Methods Appl Mech. Eng 254, 353-369 (2013). https://doi.org/10.1016/j.cma.2012.09.013

[22] Chao, Y.J., Qi, X., Tang ,W. Heat transfer in friction stir welding - experimental and numerical studies. J Manuf Sci Eng 125(1), 138-145 (2003). https://doi.org/10.1115/1.1537741

[23] Salloomi, K., Fully coupled thermomechanical simulation of friction stir welding of aluminum 6061-T6 alloy T-joint. J Manuf Processes 45, 746-754 (2019). https://doi.org/10.1016/j.jmapro.2019.06.030

[24] Meyghani, B., Awang, M., Emamian, S., Developing a Finite Element Model for Thermal Analysis of Friction Stir Welding by Calculating Temperature Dependent Friction Coefficient. In: Awang M. (eds) 2nd International Conference on Mechanical, 
Manufacturing and Process Plant Engineering. Lecture Notes in Mechanical Engineering. Springer, Singapore, 2017. https://doi.org/10.1007/978-981-10-4232-4_9

[25] Constantin, M.A., Boșneag, A., Nitu, E. et al. Experimental investigations of tungsten inert gas assisted friction stir welding of pure copper plates. IOP Conf. Ser.: Mater. Sci. Eng. 252 012038. CAR2017 International Congress of Automotive and Transport Engineering, 2017 November 8-10. Pitesti, Romania. doi:10.1088/1757$899 X / 252 / 1 / 012038$

[26] Zhou, N., Song, D., Qi, W. et al. Influence of the kissing bond on the mechanical properties and fracture behaviour of AA5083-H112 friction stir welds. Mater Sci Eng A 719, 12-20 (2018). https://doi.org/10.1016/j.msea.2018.02.011

[27] Zettler, R., Material Deformation and Joint Formation in Friction Stir Welding, Friction Stir Welding, Woodhead Publishing, Elsevier, Cambridge, UKpp. 42-72 (2010) https://doi.org/10.1533/9781845697716.1.42

[28] Padhy, G.K., Wu, C.S., Gao, S. Friction stir based welding and processing technologies - processes, parameters, microstructures and applications: A review, J Mater Sci Technol 34(1), 1-38 (2018). DOI: 10.1016/j.jmst.2017.11.029

[29] Zuo, D.Q., Cao, Z.Q., Cao, Y.J. et al. Thermal fields in dissimilar $7055 \mathrm{Al}$ and 2197 Al-Li alloy FSW T-joints: numerical simulation and experimental verification. Int J Adv Manuf Technol 103, 3495-3512 (2019). https://doi.org/10.1007/s00170-019-03465-z

[30] Arora, A., Zhang, Z., De, A. et al. Strains and strain rates during friction stir welding, Scr Mater, 61(9), 863-866, (2009) https://doi.org/10.1016/j.scriptamat.2009.07.015

[31] Andrade, D.G., Leitão, C., Dialami, N., et al. Analysis of contact conditions and its influence on strain rate and temperature in friction stir welding, Int J Mech Sci , 191, 2021, https://doi.org/10.1016/j.ijmecsci.2020.106095

[32] Hammelmüller F., Zehetner C. Increasing numerical efficiency in coupled eulerianlagrangian metal forming simulations, XIII International Conference on Computational Plasticity. Fundamentals and Applications - COMPLAS XIII , 2015 (Barcelona, Spain)

[33] Gih-Keong Lau, F.L. Johannes Goosen, Fred van Keulen, Thermo-elastic behavior of a polymeric layer bonded between rigid interfaces, Int J Solids Struct, 45(18-19), 5152-5164 (2008). https://doi.org/10.1016/j.ijsolstr.2008.05.016

[34] Ducobu, F., Rivière-Lorphèvre, E., Filippi, E. On the introduction of adaptive mass scaling in a finite element model of Ti6Al4V orthogonal cutting, Simul Modell Pract Theory, 53, 1-14 (2015). https://doi.org/10.1016/j.simpat.2015.02.003

[35] Mironov, S., Inagaki, K., Sato, Y.S. et al. Microstructural evolution of pure copper during friction-stir welding, Philos Mag, 95(4), 367-381(2015). https://doi.org/10.1080/14786435.2015.1006293 
[36] Xu, N., Ueji, R., Fujii,H. Dynamic and static change of grain size and texture of copper during friction stir welding, J Mater Process Technol, 232, 90-99(2016). http://dx.doi.org/10.1016/j.jmatprotec.2016.01.021

[37] Heidarzadeh, A., Saeid, T., Klemm, V et al. Effect of stacking fault energy on the restoration mechanisms and mechanical properties of friction stir welded copper alloys, Mater Des, 162,185-197, (2019). https://doi.org/10.1016/j.matdes.2018.11.050.

[38] Heidarzadeh, A., Mironov, S., Kaibyshev, R. et al. Friction stir welding/processing of metals and alloys: A comprehensive review on microstructural evolution, Prog Mater Sci, 117, (2021). https://doi.org/10.1016/j.pmatsci.2020.100752

Table 1. Physical properties of the DHP Copper [19]

\begin{tabular}{ccccccc}
\hline Material & $\begin{array}{c}\text { Elastic } \\
\text { modulus } \\
{[\mathrm{GPa}]}\end{array}$ & $\begin{array}{c}\text { Poisson's } \\
\text { ratio }\end{array}$ & $\begin{array}{c}\text { Density } \\
{\left[\mathrm{kg} / \mathrm{m}^{3}\right]}\end{array}$ & $\begin{array}{c}\text { Thermal } \\
\text { conductivity } \\
{\left[\mathrm{W} / \mathrm{m}^{\circ} \mathrm{C}\right]}\end{array}$ & $\begin{array}{c}\text { Specific } \\
\text { heat } \\
{\left[\mathrm{J} / \mathrm{Kg}^{\circ} \mathrm{C}\right]}\end{array}$ & $\begin{array}{c}\text { Thermal } \\
\text { expansion } \\
\text { coefficient } \\
{\left[10^{-6} /{ }^{\circ} \mathrm{C}\right]}\end{array}$ \\
\hline $\mathrm{Cu}$-DHP & 117.2 & 0.33 & 8913 & 388 & 385 & 16.8 \\
\hline
\end{tabular}


Table 2. Constants of Johnson-Cook's model for DHP copper

\begin{tabular}{cccccccc}
\hline Material & $\mathrm{T}_{\text {melt }}\left({ }^{\circ} \mathrm{C}\right)$ & $\mathrm{T}_{\text {ref }}\left({ }^{\circ} \mathrm{C}\right)$ & $\mathrm{A}(\mathrm{MPa})$ & $\mathrm{B}(\mathrm{MPa})$ & $\mathrm{C}$ & $\mathrm{n}$ & $\mathrm{m}$ \\
\hline DHP-Cu & 1083 & 22 & 250 & 250.4 & 0.0137 & 0.81 & 0.73 \\
\hline
\end{tabular}


Table 3 Simulation labels and speeds selected in the parametric study

\begin{tabular}{ccccc}
\hline $\boldsymbol{v}_{\boldsymbol{a}}[\mathrm{mm} / \mathrm{min}]$ & $\mathbf{6 0}$ & $\mathbf{9 0}$ & $\mathbf{1 2 0}$ & $\mathbf{1 5 0}$ \\
\hline $\boldsymbol{v}_{\boldsymbol{r}}[\mathbf{r p m}]$ & & & & \\
\hline $\mathbf{1 2 0 0}$ & $\mathrm{S}-60-1200$ & $\mathrm{~S}-90-1200$ & $\mathrm{~S}-120-1200$ & $\mathrm{~S}-150-1200$ \\
\hline $\mathbf{1 0 0 0}$ & $\mathrm{S}-60-1000$ & $\mathrm{~S}-90-1000$ & $\mathrm{~S}-120-1000$ & $\mathrm{~S}-150-1000$ \\
\hline $\mathbf{8 0 0}$ & $\mathrm{S}-60-800$ & $\mathrm{~S}-90-800$ & $\mathrm{~S}-120-800$ & $\mathrm{~S}-150-800$ \\
\hline
\end{tabular}


Table 4 Welding configurations tested investigated during the experimental study

\begin{tabular}{|c|c|c|c|}
\hline $\begin{array}{c}\boldsymbol{v}_{\boldsymbol{a}}[\mathrm{mm} / \mathrm{min}] \\
v_{r}[\mathrm{rpm}]\end{array}$ & 90 & 120 & 150 \\
\hline 1200 & $\mathrm{~W}-\mathbf{9 0 - 1 2 0 0}$ & & $\mathrm{W}-\mathbf{1 5 0 - 1 2 0 0}$ \\
\hline $\mathbf{1 0 0 0}$ & $\mathrm{W}-\mathbf{9 0 - 1 0 0 0}$ & $\mathrm{W}-\mathbf{1 2 0 - 1 0 0 0}$ & $\mathrm{W}-\mathbf{1 5 0 - 1 0 0 0}$ \\
\hline 800 & $\mathrm{~W}-90-800$ & & $\mathrm{~W}-150-800$ \\
\hline
\end{tabular}




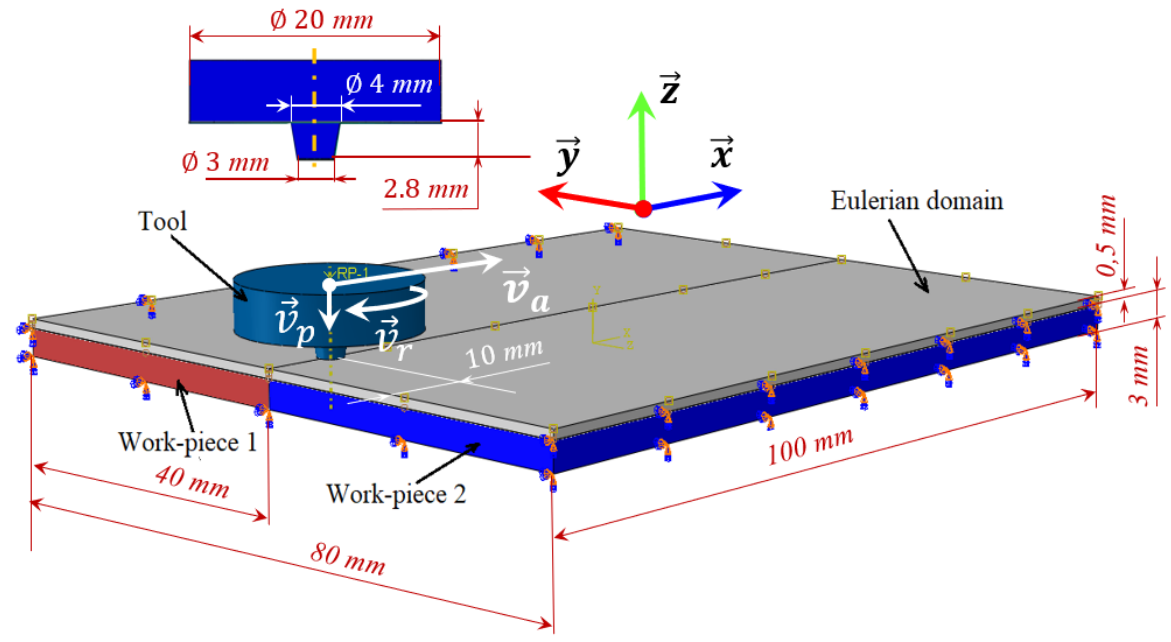

a)- Geometry and boundary conditions of the FEM

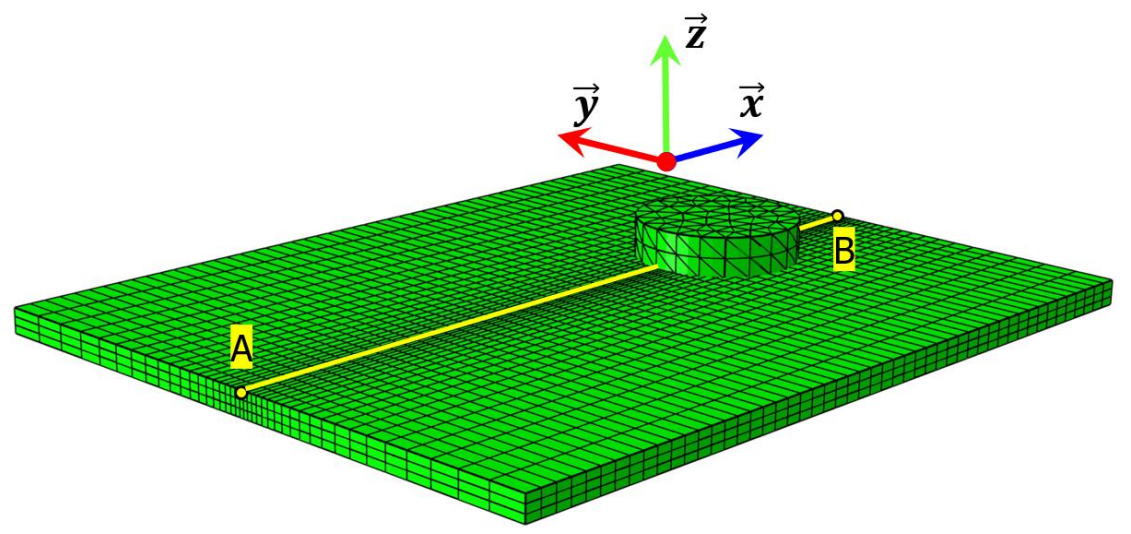

b)- Central line mesh of the FEM

Figure 1 - Geometrical model, boundary conditions, and mesh of the FEM 


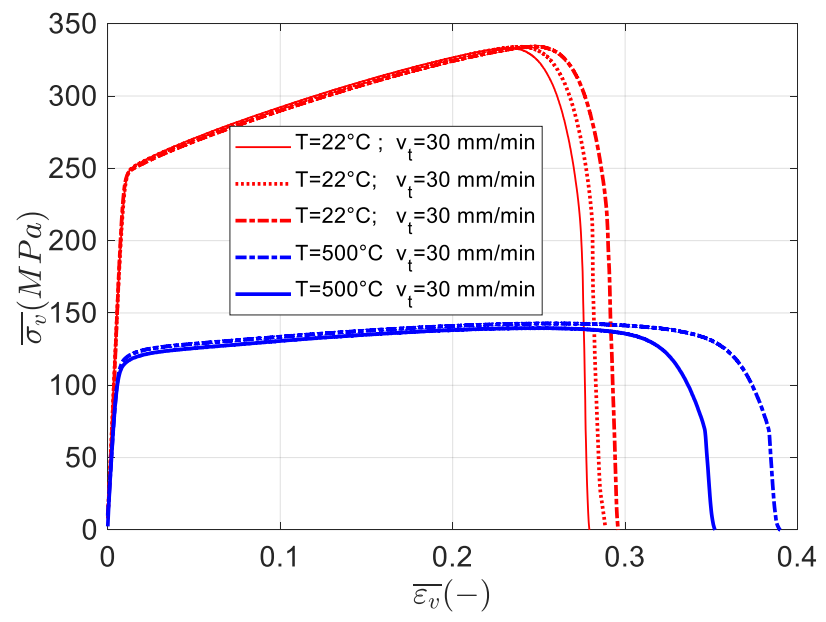

Figure 2- Macroscopic behavior of base material as a function of temperature, where $\bar{\varepsilon}_{v}$ is the logarithmic strain and $\bar{\sigma}_{v}$ is the true stress 


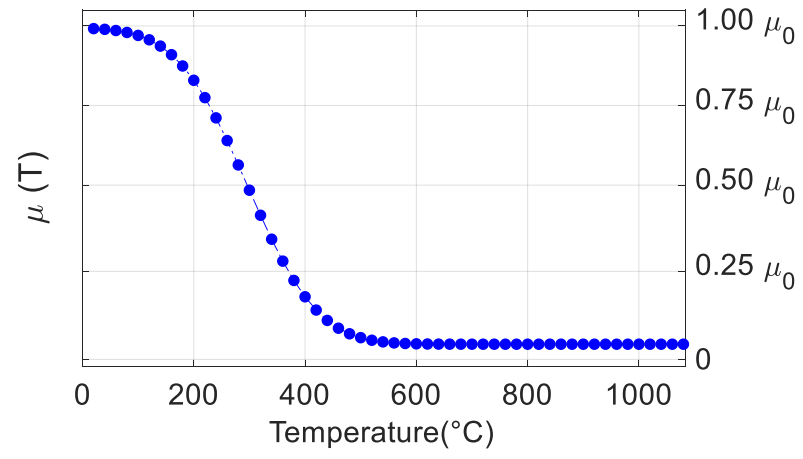

Figure 3 - Evolution of the friction coefficient as a function of temperature 


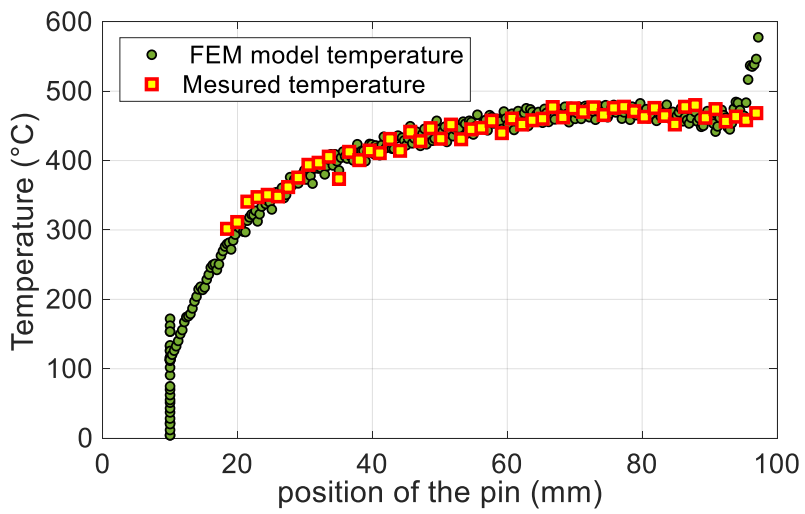

Figure 4 - Predicted versus measured temperatures against the position of the pin, in the $\vec{x}$ direction 


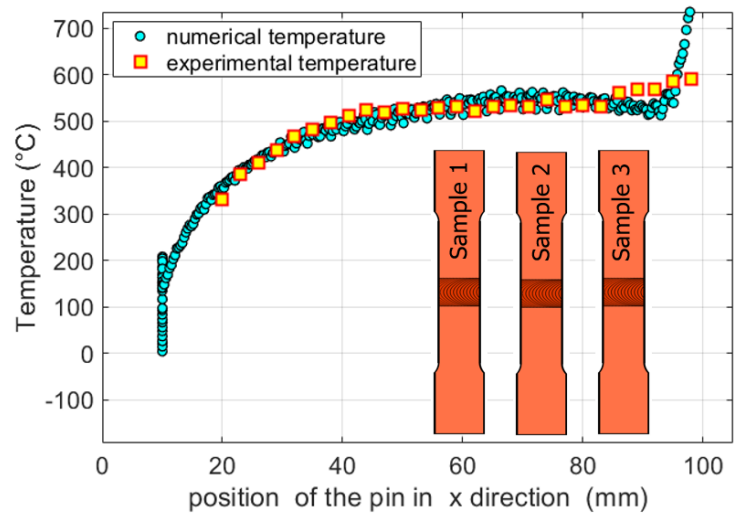

a) Comparison between numerical and experimental temperature distributions for W-90-1000 sample

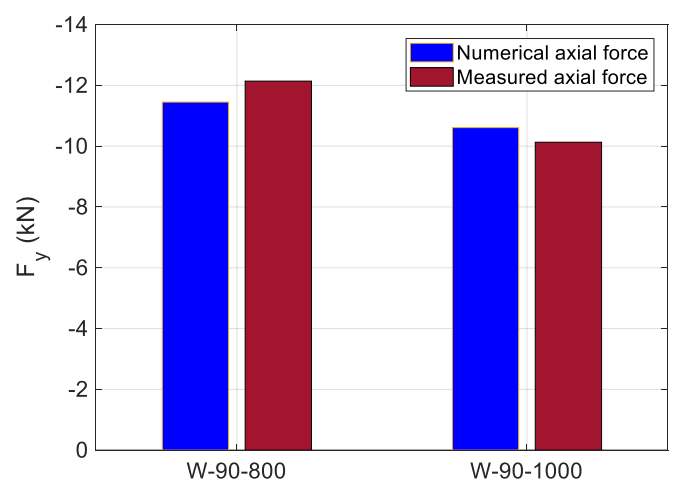

b) Comparison between numerical and experimental forces $F_{z}$, for $\mathrm{W}$ 90-800 and W-90-1000 samples

Figure 5 - Validation of the finite element method 


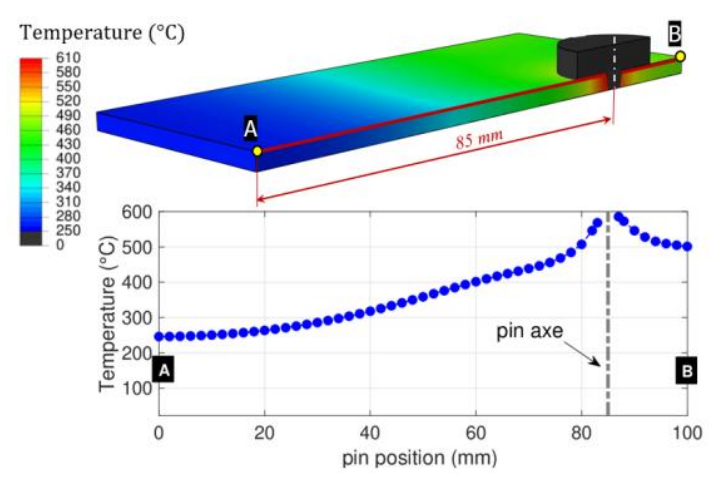

a)-distribution of the temperature from

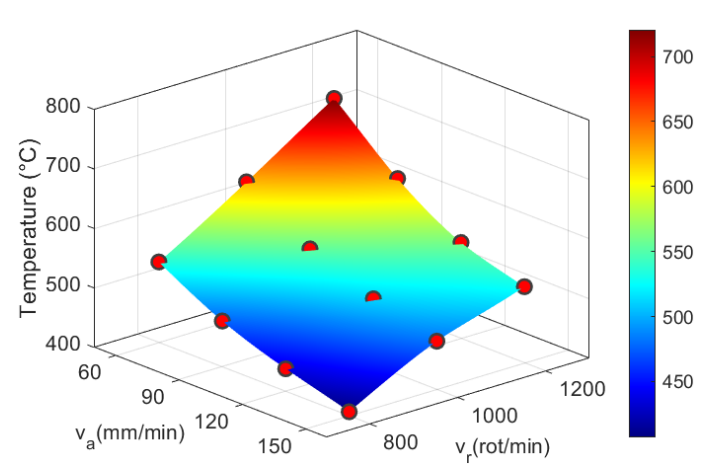

b)- stabilized surface temperature

the S-90-1200 simulation

Figure 6- surface temperature from numerical simulation 


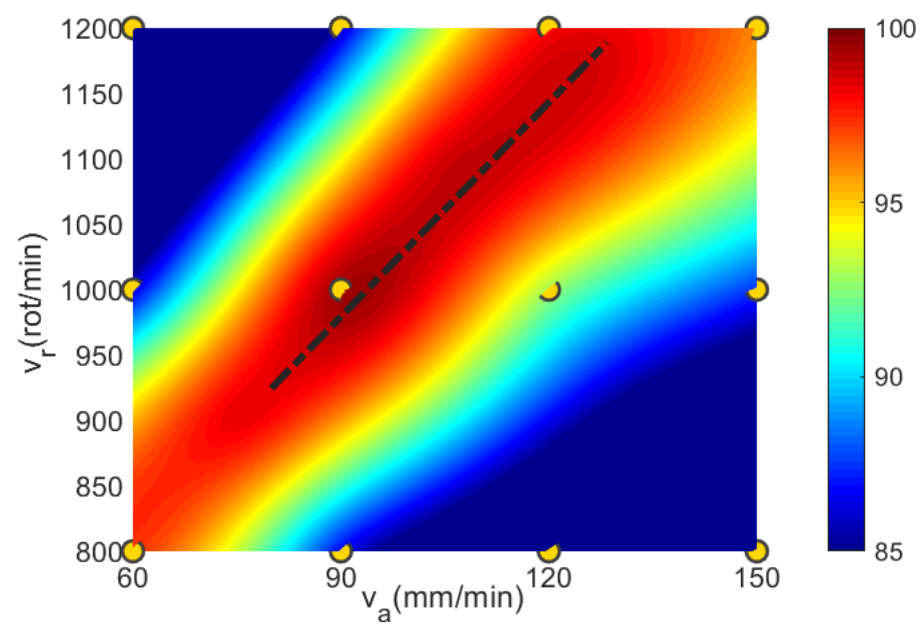

Figure 7 - thermal efficiency surface, $T_{E}\left(v_{a}, v_{r}\right)$ 


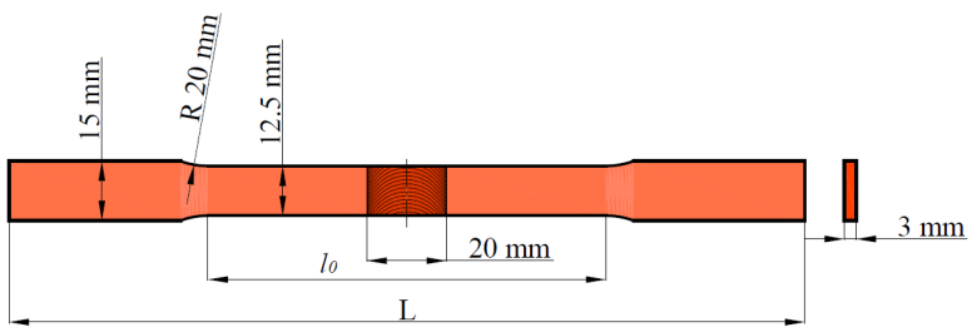

a) - Sample dimensions

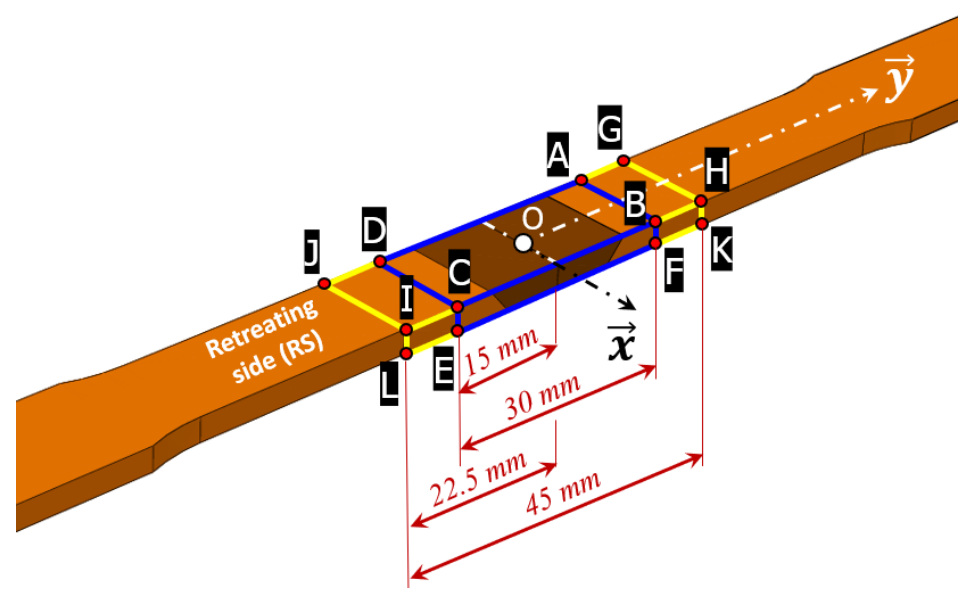

b) - Position of the X-Ray radiography and DIC investigated areas

Figure 8 - Geometry and monitored faces of the sample 


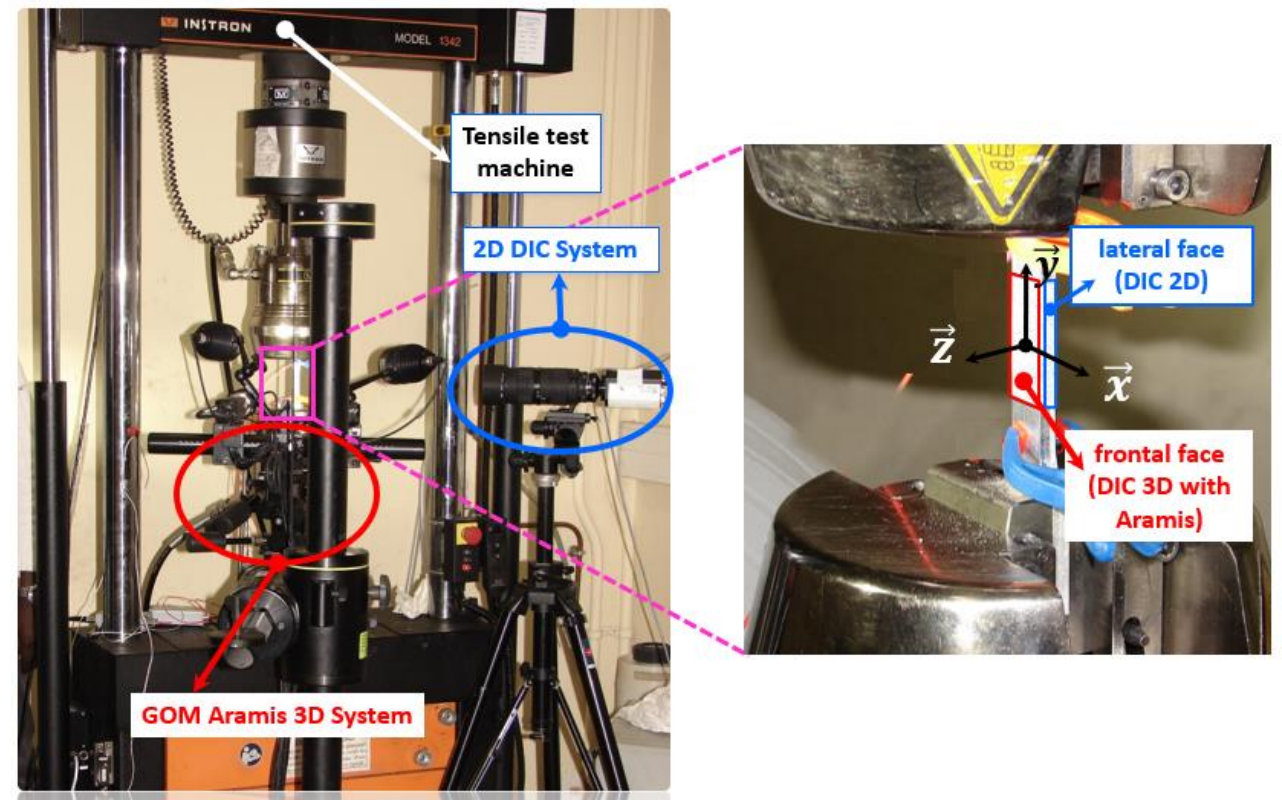

Figure 9 - Tensile test set-up to investigate the mechanical behavior of the FSW joint 


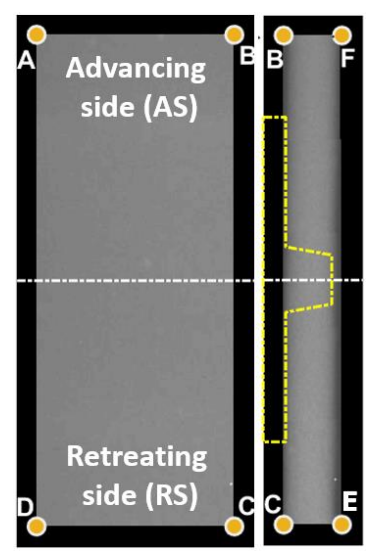

a) - W-90-1000

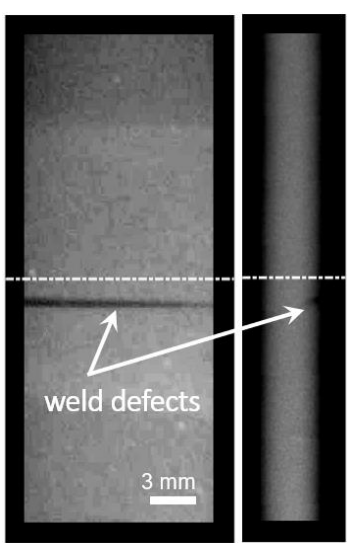

b) - W-150-1000

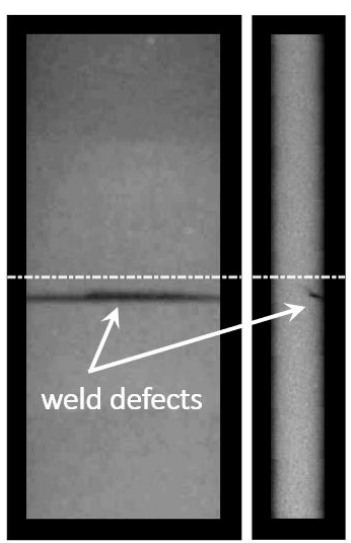

c) - W-90-800

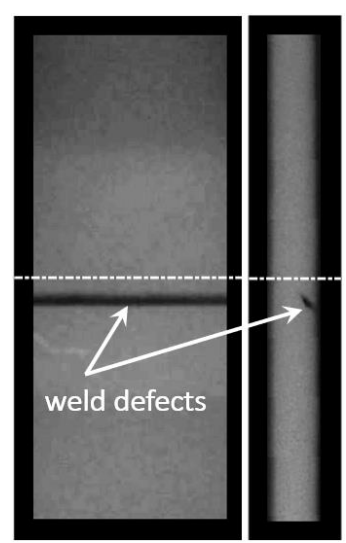

d) - W-150-800

Figure 10 - Defects identification from X-ray radiography 


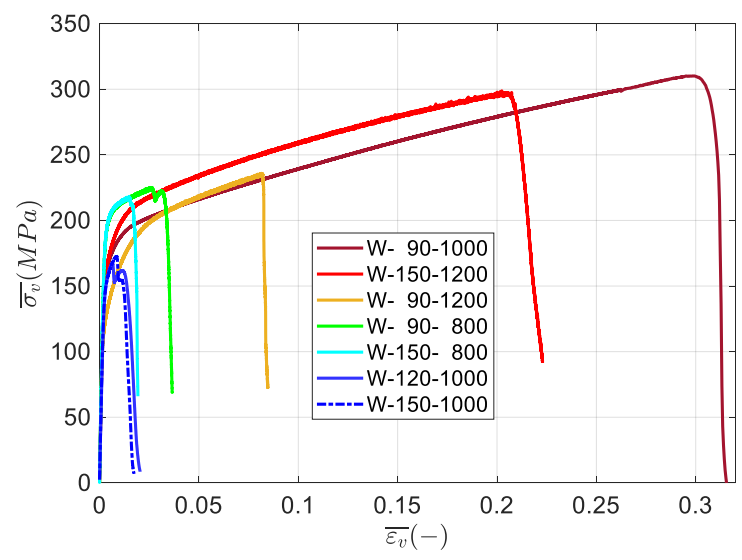

Figure 11 - Effects of process parameters: macroscopic behavior of the welded joint plotted in the plane true strain $\left(\overline{\varepsilon_{v}}\right)$ versus true stress $\overline{\sigma_{v}}(M P a)$ 


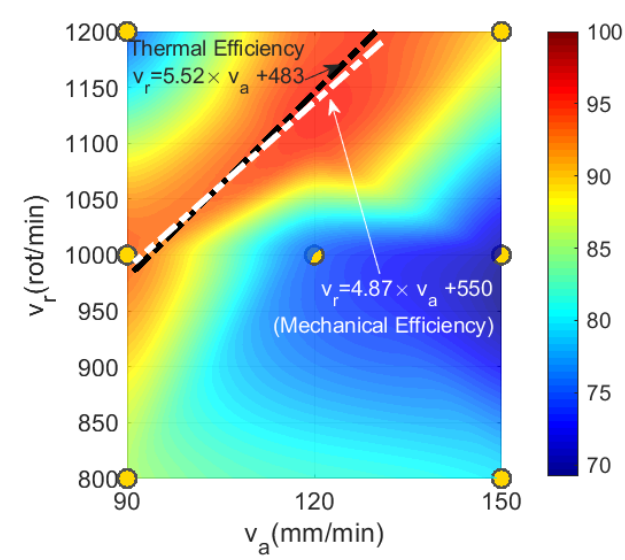

a) - Mechanical efficiency $\left(E_{M}\right)$ compared with the thermal one $\left(T_{E}\right)$

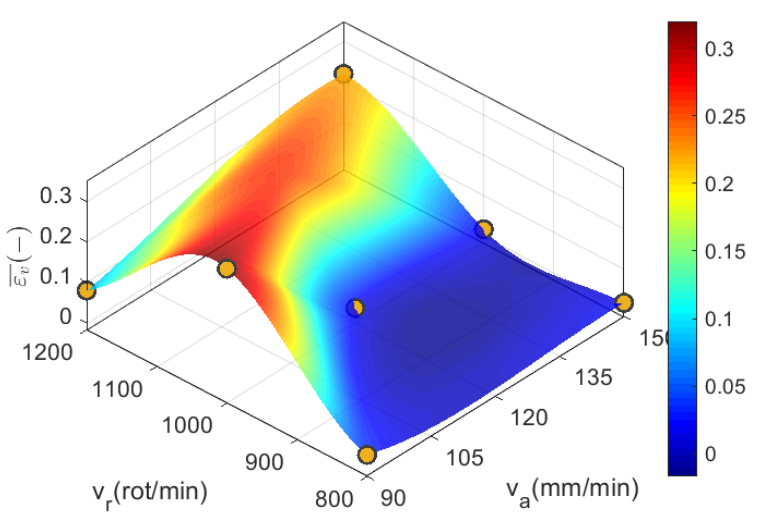

b) - Maximum strain $\left(\bar{\varepsilon}_{v} \max F S W\right)$ as a function of the welding speeds $\left(v_{a}, v_{r}\right)$

Figure 12 - Correlation between the optimal welding speeds and the resulting maximum strain of the FSW assembly 


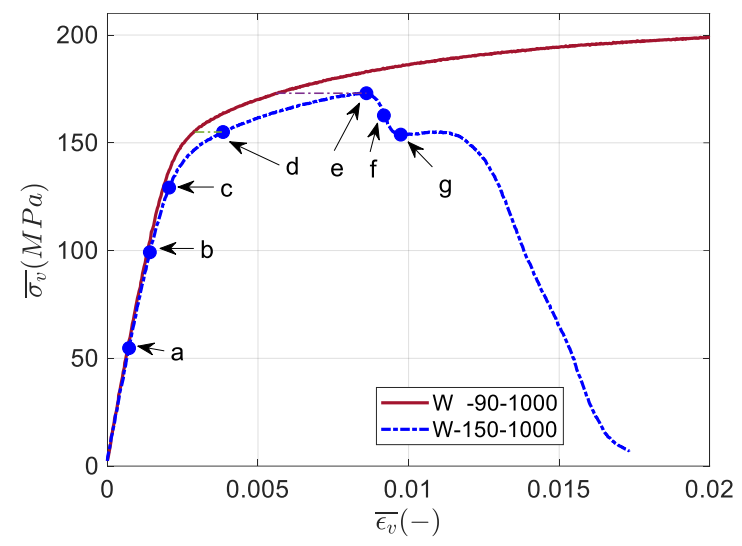

a) - Macroscopic mechanical behavior of two specimens

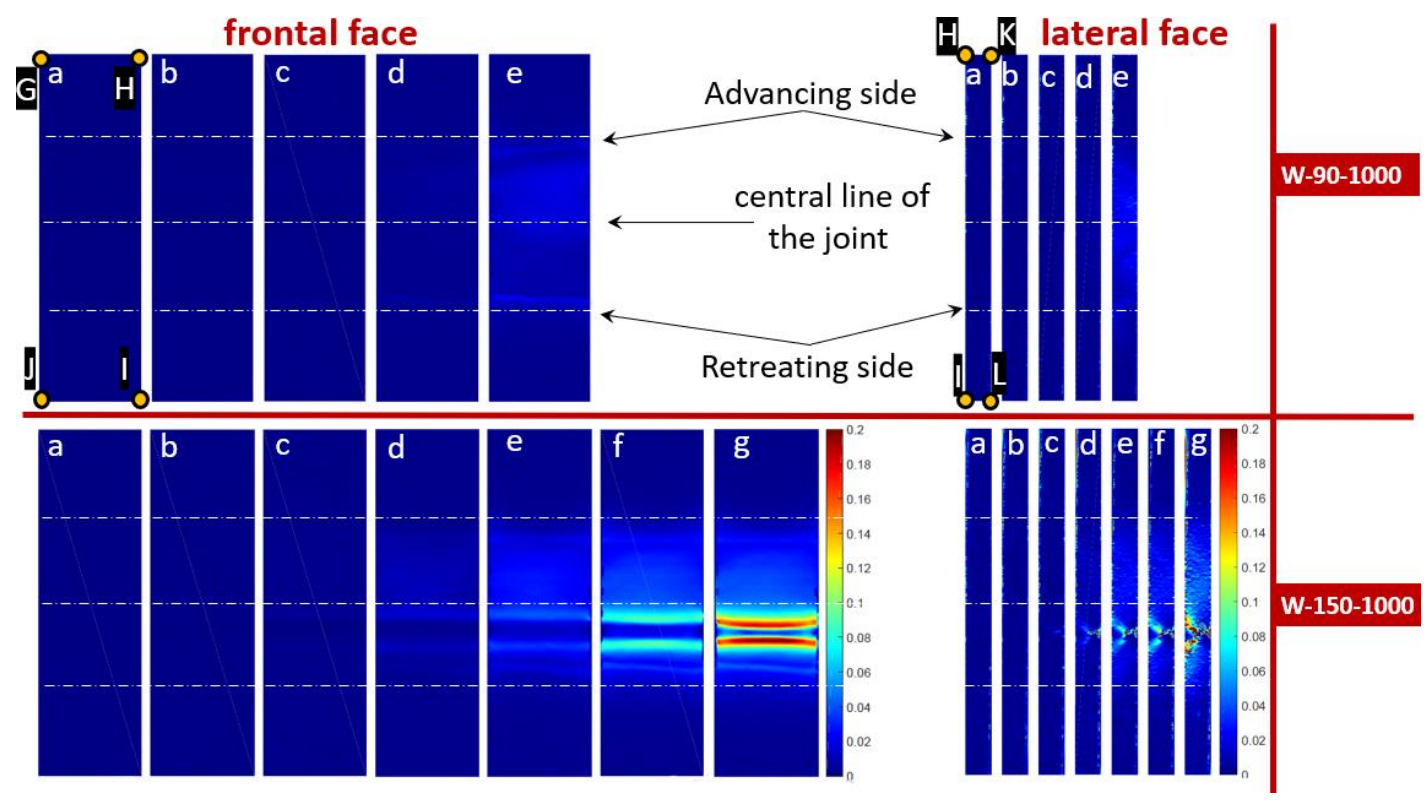

b) - Local strain maps in the loading direction of two specimens

Figure 13 - Strain maps comparison between W-90-1000 and W-150-1000 samples 

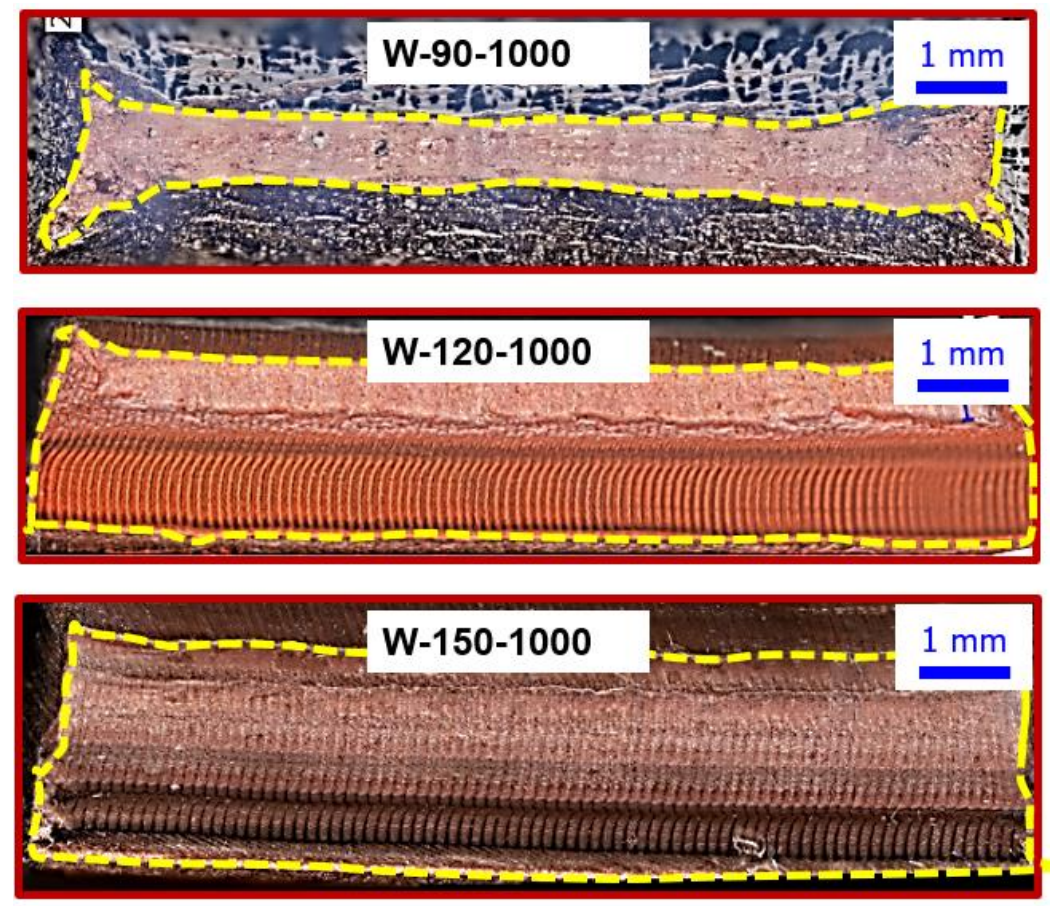

Figure 14 - Fracture surface analysis of three welded joints 


\begin{tabular}{|c|c|c|c|}
\hline$V r \downarrow$ & $V a \rightarrow 90 \mathrm{~mm} / \mathrm{min}$ & $120 \mathrm{~mm} / \mathrm{min}$ & $150 \mathrm{~mm} / \mathrm{min}$ \\
\hline 1200 (rpm) & $\|^{\text {AS }}$ \& $\quad \vdots$ & & Prg \\
\hline 1000 (rpm) & 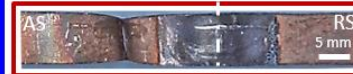 & $\begin{aligned} R S \\
5 \mathrm{~mm}\end{aligned}$ & ${ }^{\mathrm{RS}}$ \\
\hline 800 (rpm) & \begin{tabular}{|l|r|r}
$\mathrm{As}$ & $\mathrm{RS}$ \\
& $\mathrm{smm}$ \\
\end{tabular} & & $\begin{array}{ll}\text { AS } & \vdots \\
& \vdots\end{array}$ \\
\hline
\end{tabular}

Figure 15 - fracture path localization 


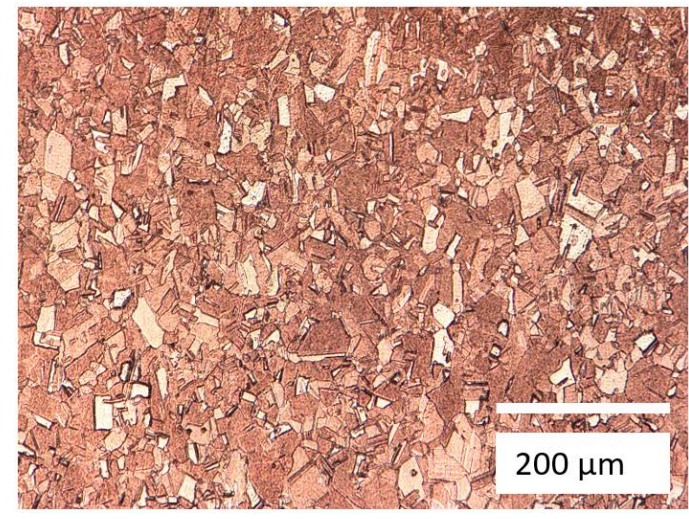

a) microstructure of the base material

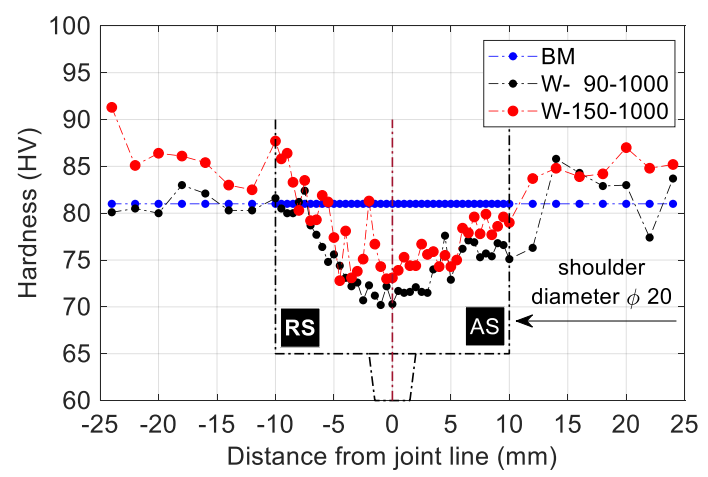

c- welding joints microhardness for $\mathrm{W}$ 90-1000 and $W-150-1000$ configurations

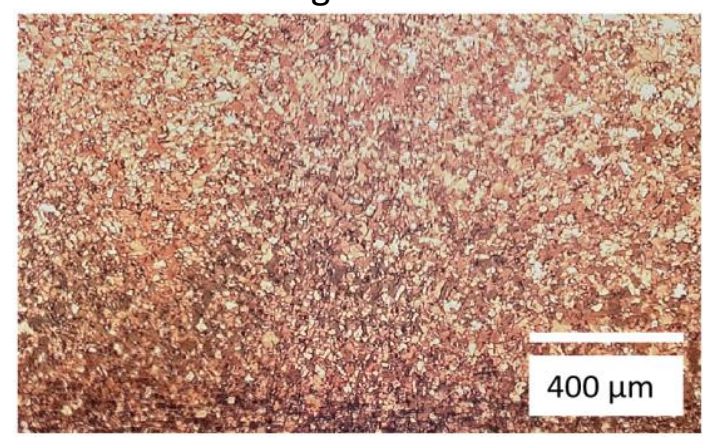

e) microstructure of the root of the weld bead (configuration W-90-1000)

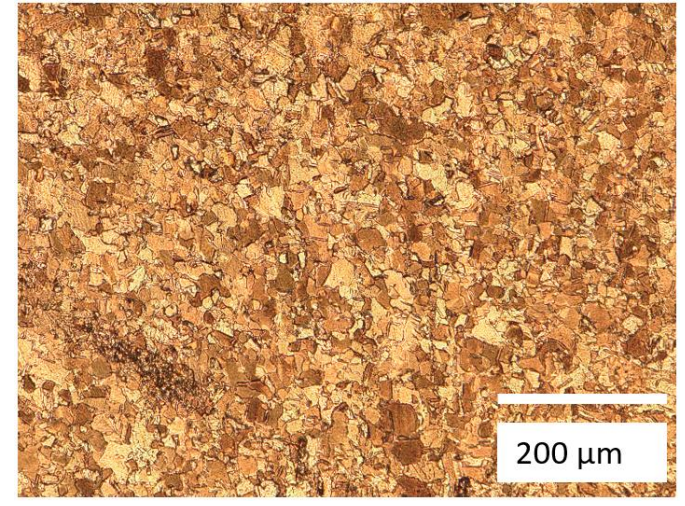

b) microstructure of the weld nugget (configuration W-90-1000)

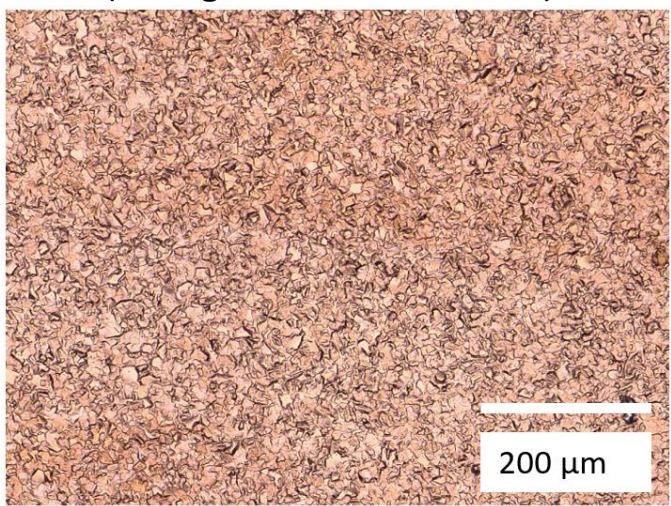

d) microstructure of the weld nugget (configuration W-150-1000)

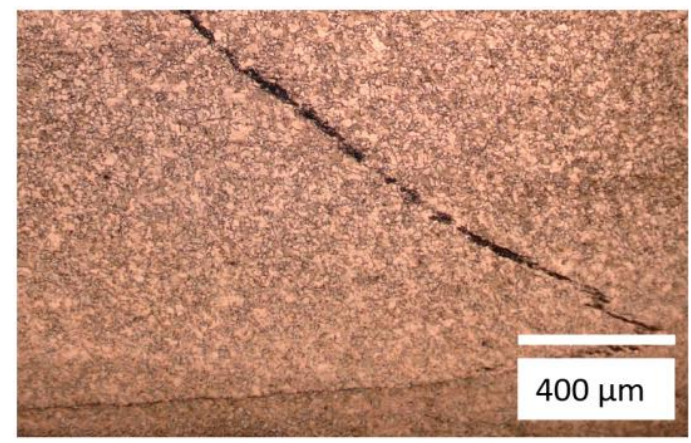

f) microstructure of the root of the weld bead (configuration W-1501000)

Figure 16-Microstructure and microhardness of the welds for different process parameters 


\section{List of Figures (figure captions)}

Figure 1 - Geometrical model, boundary conditions, and mesh of the FEM

Figure 2 - Macroscopic behavior of base material as a function of temperature, where $\overline{\varepsilon_{v}}$ is the logarithmic strain and $\bar{\sigma}_{v}$ is the true stress

Figure 3 - Evolution of the friction coefficient as a function of temperature

Figure 4 - Predicted versus measured temperatures against the position of the pin, in the $\vec{x}$ direction

Figure 5 - Validation of the finite element method

Figure 6 - surface temperature from numerical simulation

Figure 7 - thermal efficiency surface, $T_{E}\left(v_{a}, v_{r}\right)$

Figure 8 - Geometry and monitored faces of the sample

Figure 9 - Tensile test set-up to investigate the mechanical behavior of the FSW joint

Figure 10 - Defects identification from X-ray radiography

Figure 11 - Effects of process parameters: macroscopic behavior of the welded joint

plotted in the plane logarithmic strain $\left(\overline{\varepsilon_{v}}\right)$ versus true stress $\overline{\sigma_{v}}(M P a)$

Figure 12 - Correlation between the optimal welding speeds and the resulting maximum strain of the FSW assembly

Figure 13 - Strain maps comparison between W-90-1000 and W-150-1000 samples

Figure 14 - Fracture surface analysis of three welded joints

Figure 15 - fracture path localization

Figure 16 - Microstructure and microhardness of the welds for different process

parameters 